\title{
GEOLOGIA E GEQQUÍMICA DOS ELEMENTOS MAIORES DOS DEPÓSITOS DE MAGNESITA PRÉ-CAMBRIANA ( 1.8Ga) DA FAIXA MÓVEL ORÓS ( CEARÁ)
}

\author{
CLÓVIS VAZ PARENTE*, JEAN JACQUES GUILLOU** \& MICHEL HENRI ARTHAUD*
}

\begin{abstract}
GEOLOGY AND MAJOR ELEMENTS GEOCHEMISTRY OF THE PRE-CAMBRIAN ( L8Ga) MAGNESITE DEPOSITS OF THE ORÓS MOBILE BELT ( CEARÁ) The five most important magnesite mines and some small occurrences of the Ceará State form an array of discontinuous lenses extending for about $140 \mathrm{~km}$. The magnesite-rich rocks are hosted in metadolomites with lutecite, fibroradiated quartz pseudomorph after sulfate nodules, scapolite and dissolution breccias. The marbles are hosted by a metavolcanosedimentary sequence of the greenschist to amphibolite facies, and were intruded by basic sills and granites of size, form, composition and age that vary from the Meso to Neoproterozoic.

Two types of magnesite marbles may be distinguished: (1) magnesite marble of medium grain-size (1 to $9 \mathrm{~mm})$ and (2) sparry magnesite marble $(1$ to $15 \mathrm{~cm})$. The sparry magnesite marble has porphyric, rosette, layered, and palisade textures, the latter having remains of the original sedimentary features. In spite of deformation, the sparry crystals are hipidiomorphic and pinolitic. The rocks vary from white to light gray or dark gray or even red. The dark banded terms have traces of microfossils and stromatolitic structures. The texture and color of the medium-grained magnesite marbles are more homogeneous and the crystals are more anhedral. The sparry magnesite marble is in general poorer in $\mathrm{SiO}_{2}, \mathrm{Fe}_{2} \mathrm{O}_{3}$, $\mathrm{Al}_{2} \mathrm{O}_{3}$ and $\mathrm{CaO}$ and richer in $\mathrm{MgO}$ as compared to the medium-grained types.

The paleogeographic interpretation suggests that these rocks formed near a paralic system (lagoon), with strong evaporitic conditions. The depressions were of variable depth and length and probably isolated by stromatolite barriers, dried and flooded by seawater with continental inflows. The largest and deepest deposits correspond to the sparry magnesite. Regionally, the magnesite deposits give place to dolomitic marbles, which grade into almost pure calcitic marbles, indicating a chemical differentiation within the paralic system, by which the lagoon waters turned progressively poorer in $\mathrm{Ca}$ by the precipitation of calcium carbonate, thus increasing the $\mathrm{Mg} / \mathrm{Ca}$ ratio and leading to the precipitation of magnesite The magnesite marble is than interpreted as of sedimentary origin, and underwent strong diagenesis before metamorphism and Neoproterozoic deformation.
\end{abstract}

Keywords: Magnesite, Geochemical, Marble, Mobile Belt Oros

RESUMO Os cinco principais jazimentos e algumas pequenas ocorrências de magnesita do Ceará formam um rosário de lentes que se estende por cerca de $140 \mathrm{~km}$. As rochas magnesíticas são encaixadas em metadolomitos com lutecita, quartzo fibrorradiado pseudomorfo sobre nódulos de sulfates, brechas de dissolução e escapolita. O conjunto está hospedado em uma sequência metavulcanossedimentar de fácies xisto verde a anfibolito, com intrusões de sills básicos e granitos de tamanho, forma e composição variada do Mesoproterozóico (1.78Ga) ao Neoproterozóico.

Dois tipos de mármores magnesíticos podem ser distinguidos: os mármores de grão médio ( 1 a $9 \mathrm{~mm})$ e os espáticos (1 a $15 \mathrm{~cm})$. Os espáticos apresentam grandes variações texturais, com predomínio dos tipos porfirítico, em roseta, bandado e palissádico. Os últimos ainda preservam estruturas dos sedimentos originais. A sua cor varia entre o branco, cinza claro, cinza escuro e vermelho tijolo. $\mathrm{O}$ termo bandado escuro apresenta traços de microfósseis e estruturas estromatolíticas. Os mármores de grão médio, por sua vez, são mais homogéneos em textura e cor e os cristais são, em geral, xenomórficos. Em geral, os mármores espáticos são mais pobres em $\mathrm{SiO}_{2}, \mathrm{Fe}_{2} \mathrm{O}_{3}, \mathrm{Al}_{2} \mathrm{O}_{3}$ e $\mathrm{CaO}$ e mais ricos em $\mathrm{MgO}$ que seus equivalentes de grão médio.

Uma reconstituição paleogeográfica sugere que o ambiente de formação dessas rochas se aproxima de um sistema parálico, lagunar, com tendências evaporíticas marcantes. As depressões deveriam ter profundidade e comprimento variados e poderiam ser isoladas, em particular por barreiras estromatolíticas, ressecadas e inundadas por águas marinhas e, episodicamente, por águas continentais. As depressões maiores e mais profundas correspondem às ocorrências de magnesita espática. Regionalmente, esses mármores gradam para mármores dolomíticos e estes, por sua vez, para mármores calcíticos quase puros, o que sugere uma diferenciação química no sistema parálico, segundo a qual a precipitação de carbonato de cálcio resultaria em aumento da razão $\mathrm{Mg} / \mathrm{Ca}$, favorecendo a precipitação de magnesita. Os mármores ricos em magnesita são, portanto, interpretados como de origem sedimentar e foram submetidos a importantes modificações diagenéticas antes do metamorfismo e deformação neoproterozóica.

Palavras-chave: Magnesita, Geoquímica, Mármores, Faixa Móvel Orós INTRODUÇÃO A magnesita, como mineral acessório ou em corpos de pequenas dimensões sem interesse económico, é encontrada em uma série de ambientes geológicos, cuja idade se estende do Arqueano ao Cenozóico. Nos ambientes atuais ela está associada a alguns depósitos lacustres de clima árido (Lago Elton, ex. URSS; Tuz Gõlu, Turquia) e a depósitos parálicos salinos a hipersalinos (Coorong, Austrália; Sabkha El Melah, Tunísia; Sabkhas da Costa dos Piratas, Golfo Arábico) (Müller et al 1972, Von der Borg 1965, Busson \& Perthuisot 1977). E também associada a calcretes (Austrália), a lateritas desenvolvidas sobre rochas ultrabásicas, a zonas de metamorfismo de contato e a veios hidrotermais (Pohl \& Siegl 1986, Pohl 1989).

Os maiores jazimentos de magnesita são, entretanto, encaixados em terrenos proterozóicos e paleozóicos associados às rochas sedimentares, conhecidos como do tipo Veitsch (Pohl \& Siegl 1986, Pohl 1989). Todavia, a origem dos depósitos de magnesita do tipo Veitsch é ainda discutível. Duas hipóteses são consideradas: 1-Formação Singenética ou Sedimentar; 2- Formação Epigenética ou Metassomática.

A maior parte dos modelos que admite a magnesita como de origem sedimentar, isto é, formada a partir da precipitação direta de carbonatos, é inspirado nos sistemas sedimentares recentes, ver entre outros: Rumpf (1873 in Pohl \& Siegl 1986), Rosza (1925 in Pohl \& Siegl 1986), Nishihara (1956), Forbes (1961), Gomes de Llarena 1968, Valdiya (1968), Perry \&Tan (1972), Quéméneur(1974), Doval et al, (1977), Guillou (1972, 1973, 1980), Chaye d'Albissin \& Guillou (1985,1986,1988), Chaye d'Abissin et al. (1988) Crick \& Muir (1980 in Aharon 1988), Brunel et al. (1984), Siegl (1984), Pohl \& Siegl (1986), Pohl (1989, 1990), Velasco et al. (1987), Guillou \& Letolle (1988), Qiusheng, (1988), Schutz \& Valtar (1989), Almeida (1989), Tufar et al(1989) e Niedermayr et al. (1989). No grupo dos metasso-

matistas, que consideram a magnesita oriunda da introdução de ions $\mathrm{Mg}^{2+}$ nos calcários ou dolomitos precursores, encontram-se, entre outros, Koch (1893, Redlich 1904, 1911, Petraschek 1932 in Pohl \& Siegl 1986), Bodenlos (1948, 1954), Rosemberg \& Mills (1966), Anfimov et al. (1980),Frost(1982), Morteani et al. (1982,1983), Bone (1983), Aharon (1988), Morteani (1989), Kralik et al, (1989), Möller (1989), Preinfalk et al. (1993).

Uma das ferramentas de estudo que tem sido utilizada na caracterização desses jazimentos é a geoquímica, cujos estudos tem-se multiplicado nos últimos anos, particularmente sobre os elementos menores e traços (cf. Möller 1989, Tufar et al. 1989). O conhecimento dos elementos maiores é igualmente importante, sobretudo por parte das empresas que exploram magnesita, as quais analisam comumente $\mathrm{SiO}_{2}$ $\mathrm{Fe}_{2} \mathrm{O}_{3}, \mathrm{Al}_{2} \mathrm{O}_{3}, \mathrm{MgO}$ e $\mathrm{CaO}$ (Pohl \& Siegl 1986).

$\mathrm{O}$ presente trabalho sobre as rochas metacarbonáticas magnesianas da Faixa Móvel Orós, de idade mesoproterozóica $(\sim 1.8 \mathrm{Ga})$, permite rever alguns conceitos tradicionais sobre a geologia e a génese das rochas carbonáticas magnesianas pré-cambrianas e, desta forma, contribuir para um melhor conhecimento sobre a formação dos depósitos de magnesita.

\section{GEOLOGIA DOS DEPÓSITOS DE MAGNESITA}

depósitos principais e algumas ocorrências de magnesita do Ceará formam um rosário de lentículas que se integram dentro de um conjunto metacarbonático descontínuo, que se prolonga por mais de $140 \mathrm{~km}$, entre Pio IX, (PI), a oeste, e Orós, (CE) a leste (Fig. 1). Todas essas rochas metacarbonáticas são intercaladas em uma sequência metavulcanossedimentar de fácies xisto verde à anfibolito, recortada por granitos do Mesoproterozóico e Neoproterozóico e por corpos básico-

* Departamento de Geologia da UFC. Bloco 912, Campus do PICI- CEP: 60 455-050-Fortaleza/CE. E-mail: clovis@ufc.br;

** guillou@chimie.univ-nantes.fr 


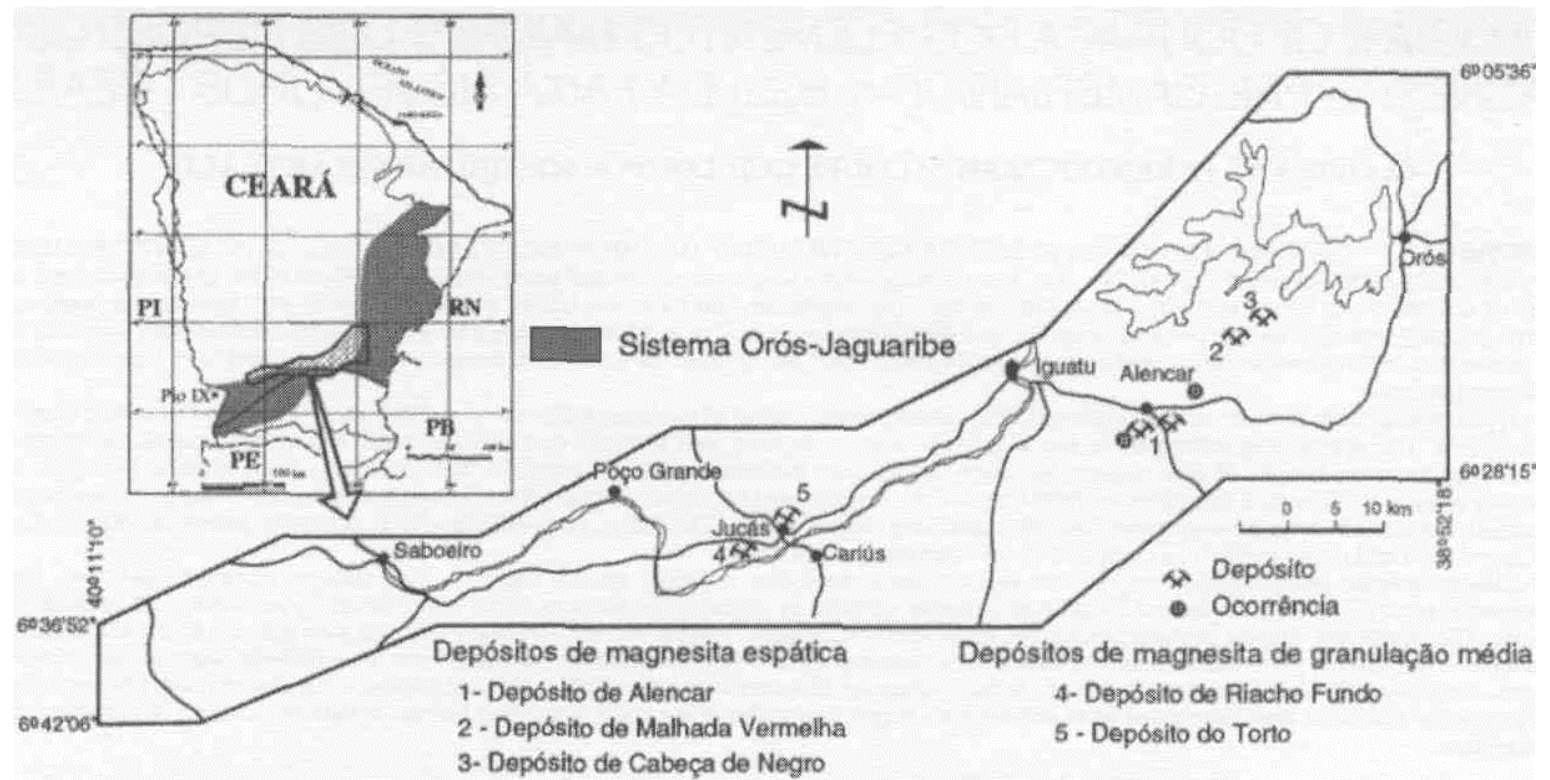

Figura l-Mapa de localização dos depósitos e ocorrências de magnesita do Ceará, Brasil.

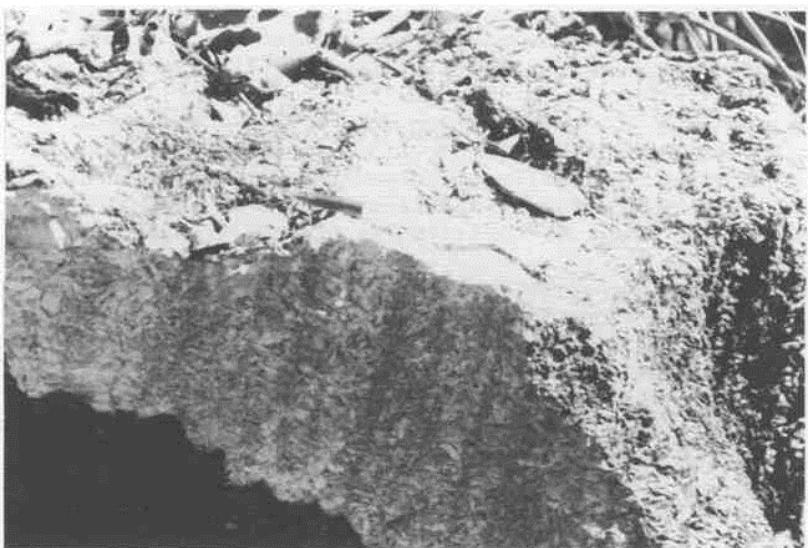

Figura 2 - Afloramento de mármore magnesítico espático com estrutura palissádica. Notar a estratificação Só marcada pela alternância de delgados níveis de matéria orgânica elou pelítico (cinza escuro) com niveis mais espessos de magnesita espática (cinza claro). Depósito de Cabeça de Negro.

ultrabásicos do Neoproterozóico. Datações geocronológicas (método $\mathrm{U} / \mathrm{Pb}$ ) sobre alguns metariólitos que se encontram intercalados aos metassedimentos tem revelado idades em torno de 1800Ma (Sá 1991, Van Schumus et al. 1995), correspondendo provavelmente à idade da sedimentação.

Os metassedimentos são sobretudo pelíticos, formados em particular por xistos aluminosos que apresentam em seu seio intercalações de quartzitos, mármores calcíticos, dolomíticos e magnesíticos, rochas cálcissilicáticas e quartzitos carbonosos. Estes últimos indicam um ambiente confinado rico em matéria orgânica, o que era pouco comum à época. Tais conjuntos litológicos apresentam uma direção principal NE-SW na parte centro-oeste, N-S na parte central da faixa e NE-SW no extremo norte da Faixa. Para maiores detalhes sobre a estratigrafia desta região consultar Parente (1995) e Parente \& Arthaud (1995).

Dois tipos de mármore magnesítico podem ser distinguidos: 1-os mármores magnesíticos espáticos $(2$ a $15 \mathrm{~cm})$ e 2- os mármores magnesíticos de grão médio (l a $9 \mathrm{~mm})$.

CARACTERÍSTICAS DOS DEPÓSITOS DE MAGNESITA

ESPÁTICA Os jazimentos de magnesita espática (Alencar, Malhada Vermelha e Cabeça Negro) (Fig. l) e algumas ocorrências estão localizados na porção centro-leste, entre a região de Alencar e Orós. Eles formam um rosário de lentículas descontínuas com cerca de $25 \mathrm{~km}$ de extensão. O tamanho dessas lentículas é variável, indo de 20 a 900 metros de comprimento e 10 a $200 \mathrm{~m}$ de largura. Os maiores depósitos estão localizados na região de Alencar. Entretanto, os que melhor apresentam as estruturas primárias correspondem aos da região de Cabeça de Negro.

Os mármores magnesíticos são encaixados e acompanhados de mármore dolomítico, em que se verificam localmente o desenvolvimento de lutecita, escapolita, nódulos de sulfatos pseudomorfizados por cristais fibrorradiais de quartzo, brechas de dissolução e mármore dolomítico com textura petalóide. Toda essa associação indica que condições evaporíticas reinaram ao seio das rochas encaixantes dos magnesititos. Para maiores informações sobre associações evaporíticas antigas, consultar, entre outros, Shaw (1960), Hietanen (1967), Serdyuchenko (1975), Badham \& Stanworth (1977), Hogarth \& Griffin (1978), Leake \& Farrow (1979), Arbey (1980), Friedman (1980), Friedman \& Shukla (1980), Vanko \& Bischop (1982), Arnold \& Guillou (1983), Papaioanou \& Carotsieris (1993), Svenningsen (1994) e Parente et al. (1996).

A passagem dos mármores magnesíticos espáticos para os mármores dolomíticos é progressiva e bem definida, mas, por vezes complexa, situação em que se verifica uma mistura entre essas rochas metacarbonáticas. Isso sugere seja uma mise en place contemporânea entre estes dois tipos litológicos, seja uma substituição incompleta de um pelo outro Em adição a isso, sã̃o observados localmente, veios de magnesita espática que recortam os metadolomitos.

Os mármores magnesíticos espáticos apresentam grandes variações texturais, cujos termos porfiríticos, roseta, bandado ou palissádico correspondem os tipos mais frequentes (Fig. 2). Estes últimos conservam traços das estruturas dos sedimentos originais. No termo bandado são encontrados, algumas vezes, traços de microfósseis, enquanto outros tipos apresentam estruturas estromatolíticas. O tamanho dos cristais varia de 1 a 15 centímetros e eles são em geral idiomórficos ou automórficos. A cor dessas rochas é variável, indo de branca, cinza clara, cinza escura, rósea a vermelho tijolo.

Do ponto de vista mineralógico, podem ser encontrados associados aos magnesititos, além da magnesita, clorita, talco, pirita e óxido de ferro. Entretanto, alguns níveis de magnesitito são muito ricos em sílica (21\%), sob a forma de talco e clorita, enquanto outros são ricos em óxido de ferro. Todavia, cada depósito apresenta uma particularidade.

As duas lentículas da região de Alencar (Fig.3) apresentam relíquias de estromatólitos e de microfósseis. Elas mostram ainda alguns níveis muitos ricos em sílica sob a forma combinada de talco e clorita, e outros ricos em óxido de ferro. Assim, pode-se pensar que esses jazimentos correspondem a uma zona de margem lagunar com aportes episódicos de águas continentais conduzindo a sílica e, provavelmente, o ferro. Contudo, o período de formação desses depósitos corresponde ao Paleoproterozóico/Mesoproterozóico, período de transição de uma Atmosfera Neutra Primordial para uma Atmosfera Oxigenada, em que o ciclo do ferro era bem diferente do ciclo atual, se não mostrando uma predominância do ferro ferroso - mais solúvel - no domínio supergênico, pelo menos uma abundância relativa. A presença do fácies com estromatólito poderia corresponder seja a barreiras estromatolíticas na entrada da laguna, seja a formações intralagunares. 


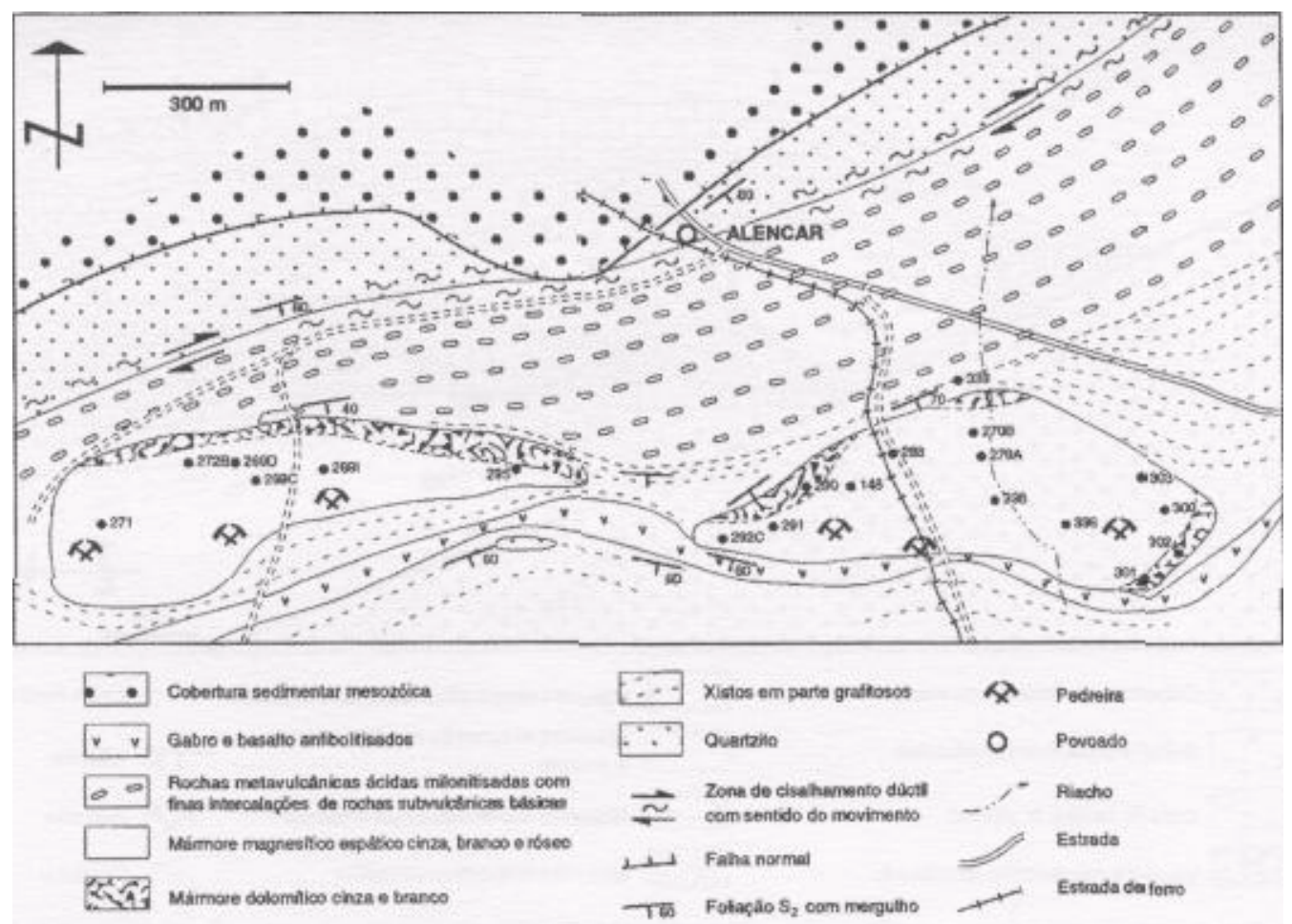

Figura 3 - Mapa geológico dos depósitos de magnesita espática da região de Alencar (modificado de Bodenlos 1948).
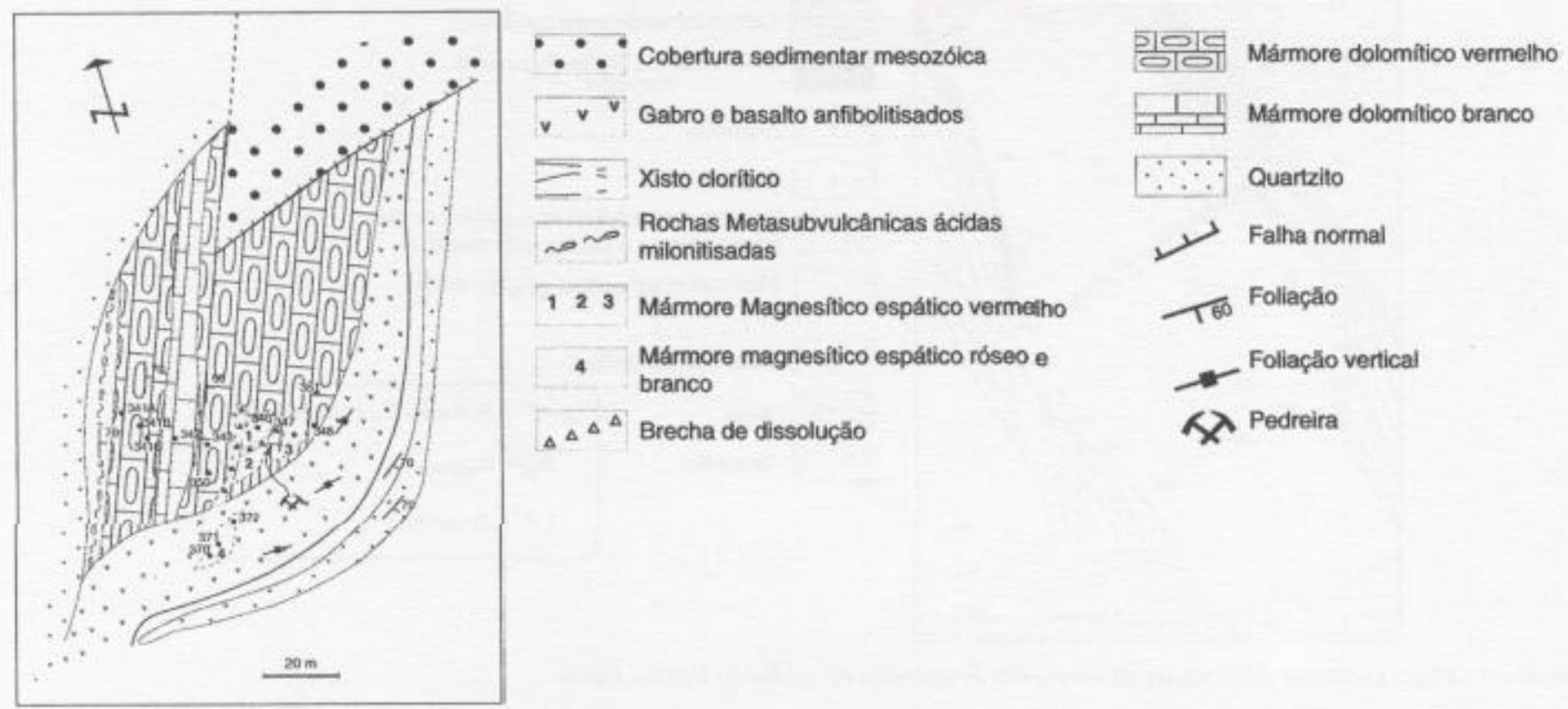

Figura 4 - Mapa geológico do depósito de magnesita espática de Malhada Vermelha.

O Depósito de Malhada Vermelha (Fig.4) é também caracterizado por termos ricos em óxido de ferro e em sílica. Nesse depósito, a passagem dos mármores magnesíticos para os mármores dolomíticos é marcada por uma camada delgada de metadolomito (lm), com nódulos de quartzo fibrorradiais ao seio de uma matriz dolomítica ferruginosa e brechada. Os nódulos são elipsoidais. Seu eixo maior varia entre 1 e $10 \mathrm{~cm}$. Eles são constituídos por cristais de quartzo fibrorradiais em rosetas, indicando tratar-se de pseudomorfos de sulfatos substituídos por sílica. Tem-se também níveis de metadolomitos mais brechados que os anteriores, característicos de brechas de dissolução encontradas em depósitos evaporíticos. Nessas brechas, encontram-se cristais de lutecita com inclusões de dolomita, algumas das quais automórficas e cúbicas, indicando tratar-se de pseudomorfos de halita substituída por dolomita.

Estas brechas parecem materializar um hiato espaço-temporal entre a deposição dos mármores dolomíticos e os mármores magnesíticos.
Pode-se interpretá-las como acumulação mais ou menos tardia de salmouras continentais na zona de contato, acompanhada da dissolução e/ou redistribuição dos evaporitos.

O Depósito de Cabeça de Negro apresenta mega e microestruturas boudinadas, em que os mármores magnesíticos, encaixados nos metadolomitos com escapolita, correspondem aos termos mais competentes ou menos deformados do conjunto (Fig. 5). Estas lentículas são caracterizadas pela predominância de estruturas rítmicas e texturas palissádicas, que refletem variações rítmicas ao seio da sedimentação carbonática. Tais variações podem estar associadas às oscilações pluriescalares do nível marinho. Encontram-se também associados a este depósito, níveis de mármore rnagnesítico e de metadolomitos ricos em óxido de ferro, em silicato de alumínio e em grãos detríticos de zircão. Tais feições podem ser interpretadas como aportes de água doce ao seio deste depósito. 


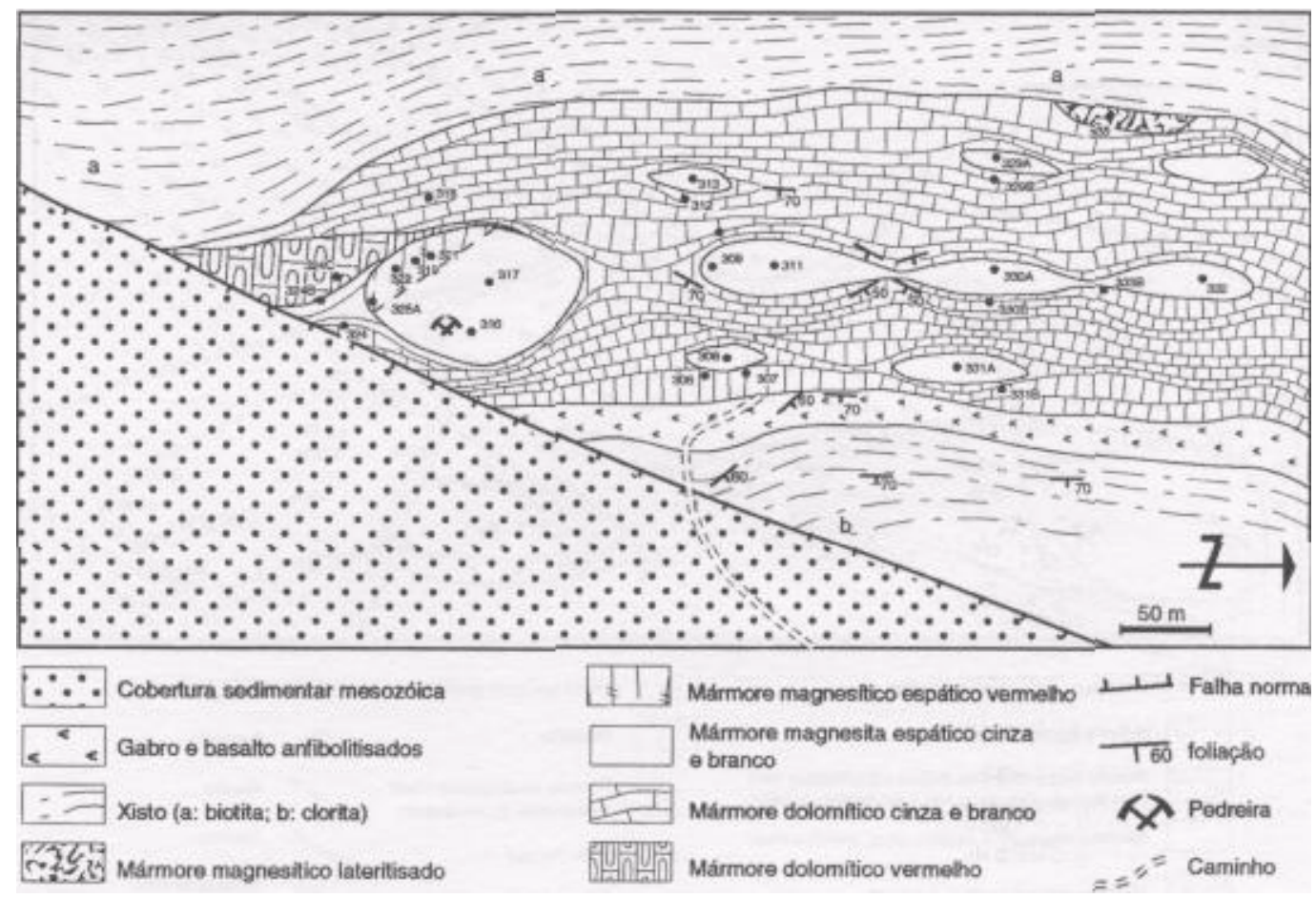

Figura 5 - Mapa geologico do deposito de magnesita espática de Cabeça de Negro.
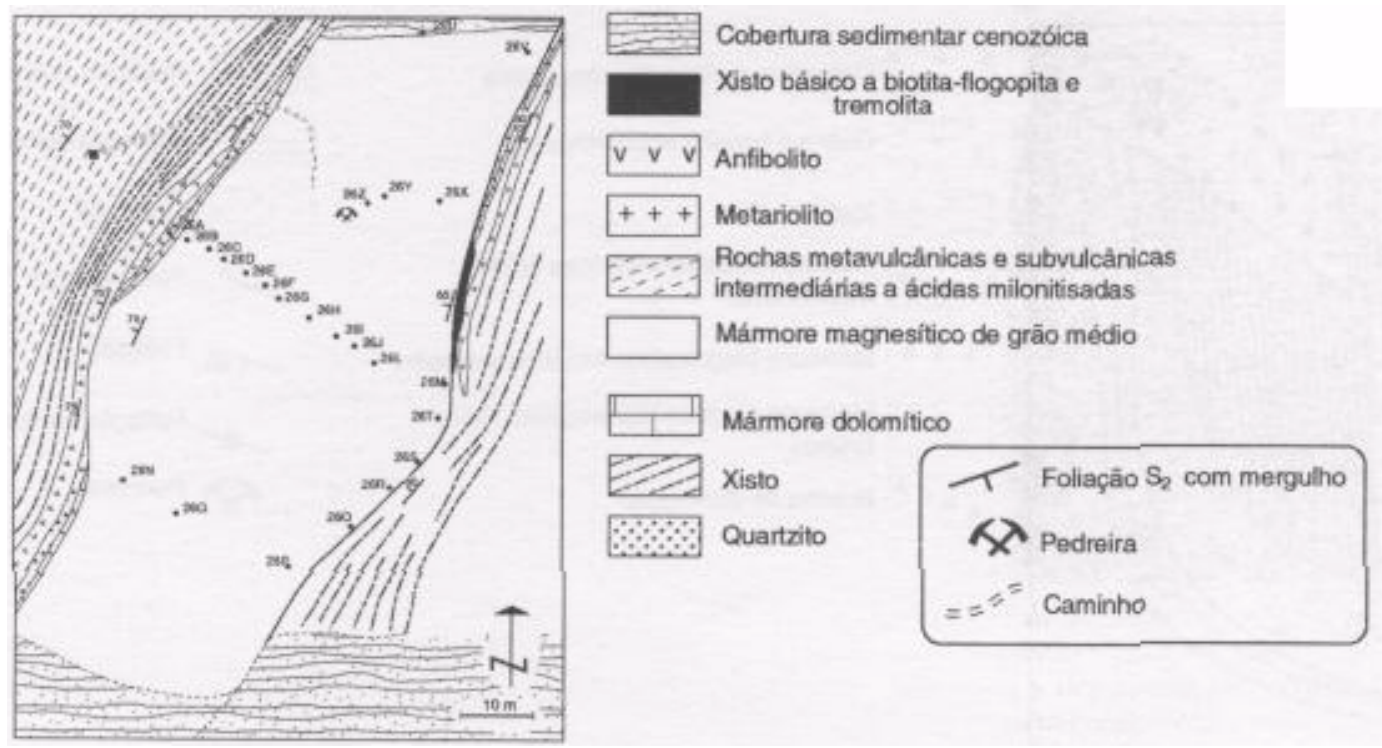

Figura 6 - Mapa geológico do depósito de magnesita de granulação média do Riacho Fundo

Todas essas características indicam que os mármores magnesíticos espáticos se formaram em sistemas parálicos, lagunares, com tendência evaporítica marcada, tendo recebido episodicamente aportes de águas doces.

\section{CARACTERÍSTICAS DOS DEPÓSITOS DE MAGNESITA}

DE GRÃO MÉDIO Os depósitos de mármore magnesítico de grão médio são representados pelas lentículas do setor centro-oeste (região de Jucás), conhecidos pelo nome de Riacho Fundo e Torto (Figs. 6 e 7). Elas ocupam duas pequenas bacias atualmente separadas por acidente estrutural, o que impede de compará-las estratigraficamente. As metavulcánicas intermediárias a ácidas e os metagranitos porfiríticos de Jucás materializam a parte central desse acidente.

Os depósitos de magnesita de Riacho Fundo apresentam uma forma lenticular e espessura irregular, dada por uma megaestrutura tipo pinch-and-swell, que é em parte condicionada por zonas de cisaIhamento dúcteis. Este depósito, embora já bastante explotado, apresenta um comprimento da ordem de $100 \mathrm{~m}$ e largura que varia de $30 \mathrm{a}$
$50 \mathrm{~m}$, cujas extremidades encontram-se recobertas por sedimentos cenozóicos. Encontra-se encaixado em metadolomitos cinza claro, xistos básicos com biotita-floglopita e tremolita e rochas cálcissilicáticas com escapolita.

Do ponto de vista petrográfico, os mármores magnesíticos são caracterizados dominantemente por um fácies com uma textura de grão fino a médio (l a $8 \mathrm{~mm}$ ), coloração branca, por vezes com manchas cinza escuras ou cinza claras refletindo a presença de minerais silicáticos. Entretanto, dois outros fácies menores podem ser determinados: um tipo com estruturas concêntricas de 3 a $6 \mathrm{~mm}$ de diâmetro que flutuam em uma matriz rica em talco e clorita (Fig. 8) e um outro, que aparece, em geral, em forma de veios, preenchendo fendas de extensão, abertas durante os cisalhamentos, caracterizado por cristais prismáticos e translúcidos de $1 \mathrm{~cm}$ de tamanho, desenvolvendo-se perpendiculares e em simetria às paredes dos níveis talco-cloritoso.

Ao microscópio, o fácies de grão fino a médio é caracterizado por uma textura granoblástica alotriomórfica composta essencialmente de magnesita. Como minerais acessórios aparecem o talco, a clorita e a 

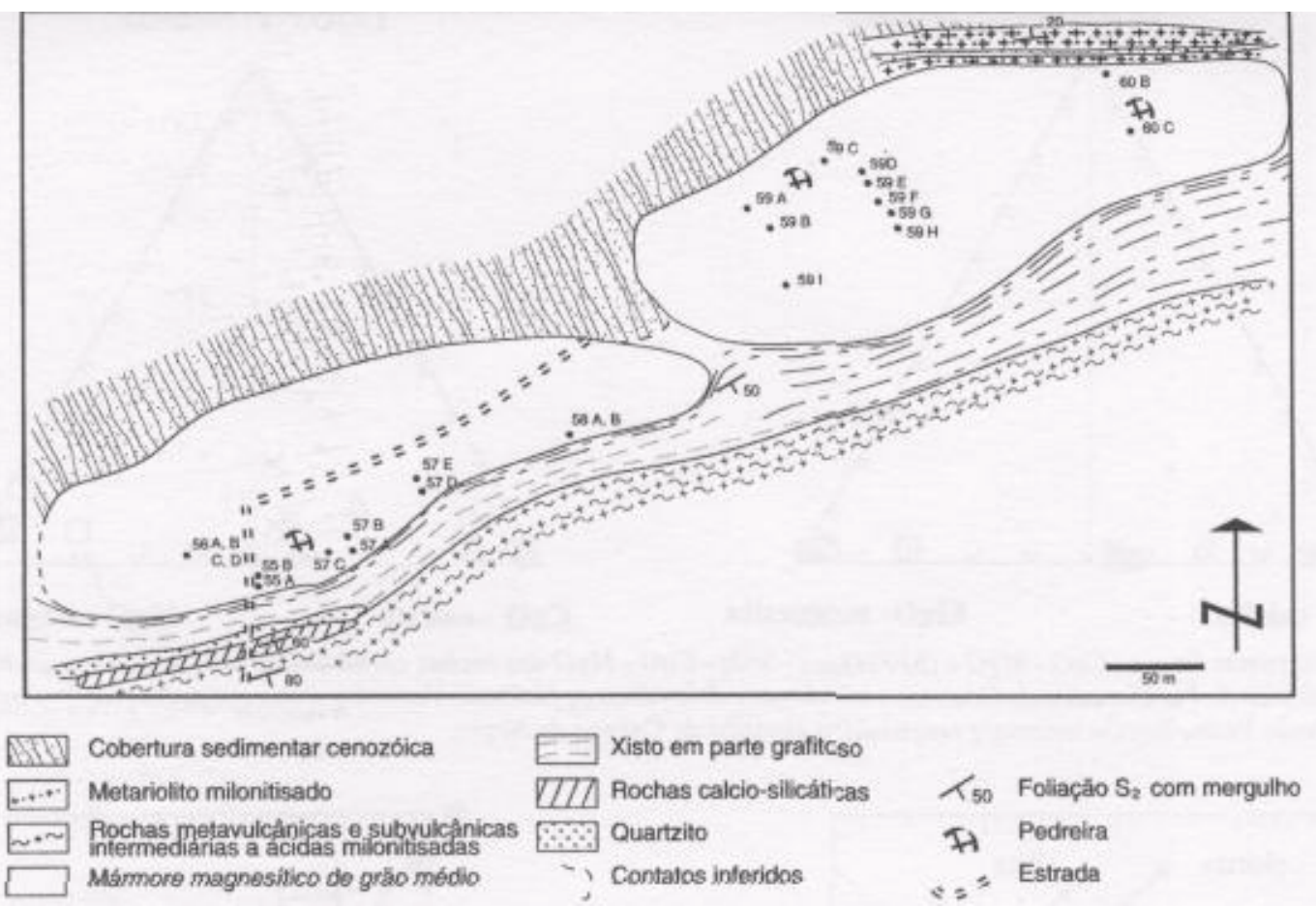

Figura 7 - Mapa geológico do depósito de magnesita de granulação média do Torto.

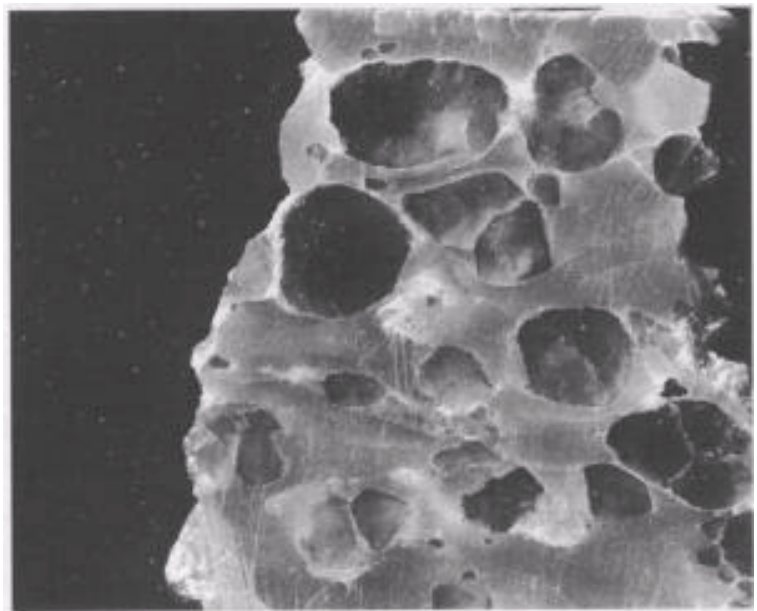

Figura 8 - Cristais ovóides de magnesita deformados em sigmóide, imersos em uma matriz rica em talco e clorita. Ao microscópico, os cristais de magnesita contém abundantes e diminutas inclusões de pirita, de origem sedimentar, testemunhando a influência de microambientes ricos em matéria orgânica (bactérias sulfato-redutoras) no ambiente salino elou penesalino. $O$ tamanho dos cristais de magnesita varia de 2 a $6 \mathrm{~mm}$.

pirita. Os cristais de magnesita, frequentemente deformados, apresentam tamanhos que vão de 0,02 a $8 \mathrm{~mm}$. Os cristais maiores são marcados por limites suturados, extinções ondulantes, bandas de deformação e recristalização em subgrãos e apresentam-se normalmente enuviados por pequenas inclusões escuras (matéria orgânica?), orientadas ou não. Já os cristais menores são frequentemente puros, com limites retos ou ligeiramente curvos e com junções tríplices. Isso indica que os cristais maiores representam os cristais reliquiares, enquanto os menores, mais volumosos, são produtos de recristalização.

O Jazimento de Torto é caracterizado por duas lentículas grosseiramente sigmoidais, de direção NE-SW, subverticais. A extensão de cada uma dessas lentículas varia entre 380 a $400 \mathrm{~m}$, enquanto a sua espessura vai de 30 a $120 \mathrm{~m}$. A passagem entre estas lentículas não é bem visível, pois encontra-se encoberta por um solo argiloso. Estas lentículas encontram-se limitadas, ao Sul, por metadolomitos, xistos, quartzitos, rochas cálcissilicáticas e metadacitos porfiríticos, enquanto ao Norte afloram níveis delgados de metariólitos e quartzitos finos milonitizados.

Do ponto de vista petrográfico, distinguem-se neste depósito basicamente dois fácies: um fácies de grão fino (1-2mm), localizado no centro da pedreira, e um fácies equigranular, bastante deformado, de grão médio (3-5mm) encontrado ao sul da lentícula SW.

Mineralogicamente, estes fácies são dominados pela magnesita, aparecendo como minerais secundários o talco, a clorita e, por vezes, a dolomita, este último em forma de veios de espessura centimétrica ao longo de fraturas.

GEOQUÍMICA DOS ELEMENTOS MAIORES E MENORES Apresentação e Discussão dos Resultados Vinte e duas amostras das rochas carbonáticas foram analisadas no Laboratório GEOLAB da GEOSOL. $\mathrm{SiO}_{2}, \mathrm{Al}_{2} \mathrm{O}_{3}, \mathrm{Fe}_{\text {total }}, \mathrm{CaO}, \mathrm{MgO}, \mathrm{MnO}, \mathrm{P}_{2} \mathrm{O}_{5}$ e $\mathrm{TiO}_{2}$ foram determinadas por Fluorescência de Raios X em amostras fundidas com $\mathrm{Li}_{2} \mathrm{~B}_{4} \mathrm{O}_{7}$. O FeO foi analisado, através de decomposição por $\mathrm{HF}+\mathrm{H}_{2} \mathrm{SO}_{4}$ em cadinho de platina tampado com liberação de $\mathrm{CO}_{2}$ e titulação do $\mathrm{FeO}$ com $\mathrm{KMnO}_{4}$ em presença de ácido bórico. Dessas amostras, 05 representam mármores calcíticos localizados na zona oeste da área, entre Cruzeta (Ce) e Pio IX (Pi), 09 amostras correspondem a mármores dolomíticos encaixantes das magnesitas espáticas, localizados na porção centro-leste, junto aos depósitos de Malhada Vermelha e Cabeça de Negro e 08 são magnesitas espáticas do Depósito de Cabeça de Negro. Das amostras correspondentes aos mármores dolomíticos, 03 são mármores dolomíticos brechados cimentados por calcita espática. A tabela 1 apresenta esses resultados.

Comportamento dos Elementos Maiores Nas figuras 9a e $9 \mathrm{~b}$, representadas pelos diagramas triangulares $\mathrm{Fe}_{2} \mathrm{O}_{3}+\mathrm{FeO}-\mathrm{CaO}-$ $\mathrm{MgO}$ e $\mathrm{Fe}_{2} \mathrm{O}_{3}+\mathrm{FeO}+\mathrm{SiO}_{2}-\mathrm{CaO}-\mathrm{MgO}$, tendo como base o trabalho de Hall \& Veizer (1 996), em que estão plotados os principais elementos das rochas carbonáticas, permitindo diferenciá-las entre si, verifica-se que as rochas estudadas plotam-se preferencialmente nos campos do mármore magnesítico, dolomítico e calcítico.

No geral, os mármores magnesíticos espáticos apresentam um teor de $\mathrm{MgO}$ variando de 39,20 a 46,60\%. Os teores mais baixos correspondem aos localizados próximo aos contatos dos metadolomitos. $\mathrm{O}$ teor de $\mathrm{SiO}_{2}$ varia de 0,47 a $7,10 \%$; o teor de $\mathrm{Al}_{2} \mathrm{O}_{3}$ vai de 0,11 ai ,30\%, o teor de $\mathrm{Fe}_{2} \mathrm{O}_{3}$ é inferior a $1 \%(0,14$ a $0,98 \%)$. O CaO varia entre 0,41 a $8,40 \%$. Os maiores valores localizam-se próximo ao contato com os metadolomitos. $\mathrm{O} \mathrm{MnO}$ varia entre 0,03 a $0,08 \%$. Os maiores valores estão também localizados próximo aos metadolomitos. $\mathrm{O}_{2} \mathrm{P}_{5}$ apresenta teores baixos e praticamente invariáveis em torno de $0,05 \%$ e o $\mathrm{TiO}_{2}$ vai de 0,05 a $0,07 \%$. 
Fe203+FeO - siderit2

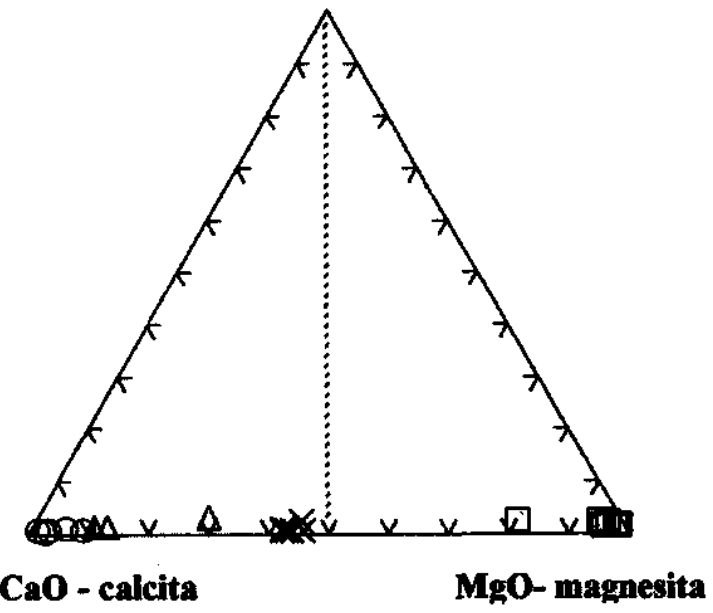

\section{$\mathrm{Fe} 2 \mathrm{O3}+\mathrm{FeO}+\mathrm{SiO} 2$}

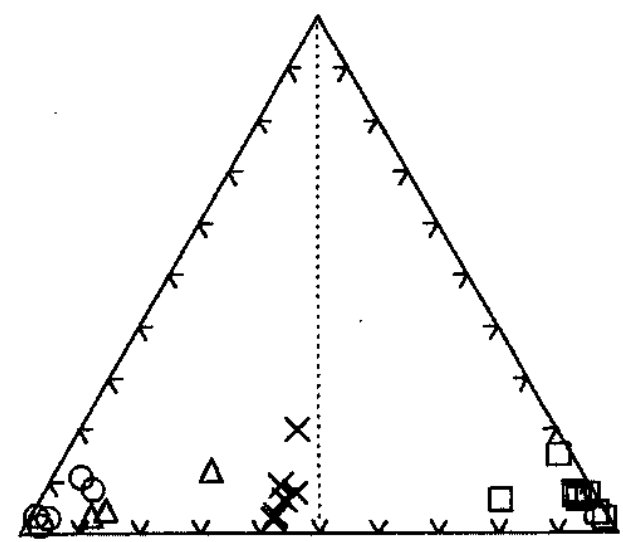

CaO - calcita
MgO- magnesita

Figura 9 - (a) Diagramas $\mathrm{Fe}_{\text {total }}-\mathrm{CaO}-\mathrm{MgO}$ e (b) $\mathrm{FeO}_{\text {total }}-\mathrm{SiO}_{2}-\mathrm{CaO}-\mathrm{MgO}$ das rochas carbonáticas da região Alencar-Pio $\mathrm{IX}$. Simbolos: $\mathrm{o}=$ mármore calcifico de Pio IX e oeste de Cruzeta; + = mármore dolomítico de Malhada Vermelha e Cabeça de Negro; $\nabla=$ mármore dolomito calcítico de Malhada Vermelha; $\square=$ mármore magnesítico espático de Cabeça de Negro.

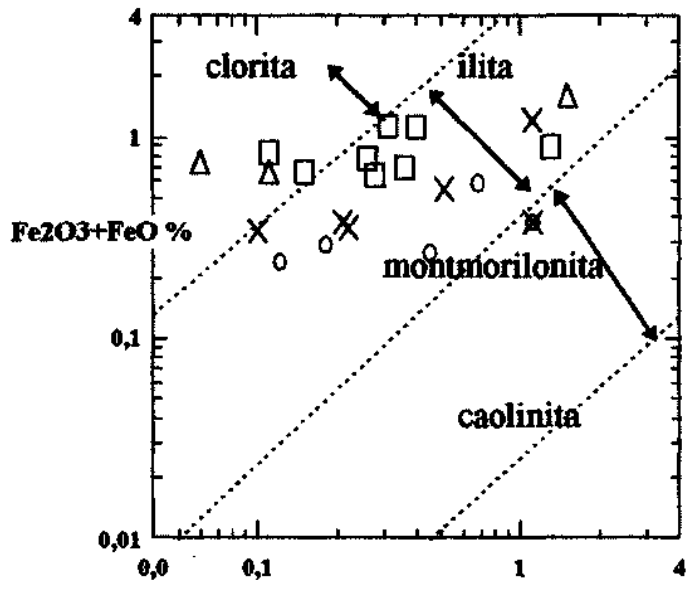

Figura 10- Diagrama $\mathrm{Fe}_{\text {total }}$ vs $\mathrm{Al}_{2} \mathrm{O}_{3}$ para as rochas metacarbonáticas da Faixa Móvel Orós. O campo dos minerais argilosos é de Deer et al. (1964, in Veizer \& Garrei 1978). Símbolos como na figura 9.

Os mármores dolomíticos, incluindo os mármores dolomíticos calcíticos, apresentam um teor de $\mathrm{MgO}$ indo de 5,70 a 23,10\%, com um teor médio de $17,69 \%$. Os teores mais baixos correspondem aos dolomitos calcíferos. $\mathrm{O}$ teor de $\mathrm{SiO}_{2}$ varia de 0,92 a $10,60 \%$, com uma média de $3,70 \%$; o teor de $\mathrm{Al}_{2} \mathrm{O}_{3}$ vai de 0,06 a $1,50 \%$, com um teor médio de $0,55 \%$ e o teor de $\mathrm{FeO}_{\text {total }}$ é inferior a $2 \%(0,24$ a 1,62$)$. $\mathrm{O}$ $\mathrm{CaO}$ varia entre 25,70 a $48,30 \%$, com um teor médio de $33,39 \%$. 0 $\mathrm{MnO}$ varia entre 0,02 a $0,37 \%$, com um teor médio de $0,12 \%$, valores bem acima daqueles encontrados associados às magnesitas espáticas. $\mathrm{O}_{2} \mathrm{O}_{5}$ vai de 0,05 a $0,11 \%$, com um valor médio da ordem de 0,06 e o $\mathrm{TiO}_{2}$ situa-se entre 0,05 e $0,18 \%$, com o valor médio de $0,07 \%$.

Os mármores calcíticos, que estão localizados mais a oeste, apresentam um teor de $\mathrm{CaO}$ indo de 47,40 a $54,10 \%$. Os teores mais baixos correspondem aos localizados próximo ao contato dos metadolomitos. $\mathrm{O}$ teor de $\mathrm{SiO}_{2}$ é relativamente baixo, variando de 0,79 a $5,70 \%$, característico de calcário de plataforma (ver, por exemplo Veizer et al. 1990); o teor de $\mathrm{Al}_{2} \mathrm{O}_{3}$ vai de 0,12 a l, $10 \%$ e o teor de $\mathrm{FeO}_{\text {total }}$ é inferior a $1 \%(0,15$ a $0,73 \%)$. O MgO vai de 0,65 a $4,60 \%$, cujos valores maiores aumentam de oeste para leste. $\mathrm{O} \mathrm{MnO}$ varia entre 0,01 a $0,02 \%$. O $\mathrm{P}_{2} \mathrm{O}_{5}$ e o $\mathrm{TiO}_{2}$ apresentam valores médio em torno de $0,05 \%$.

Estes elementos variam também conjuntamente (tabela 2). Nos mármores magnesíticos, $0 \mathrm{SiO}_{2}$ mostra uma boa correlação positiva com o $\mathrm{Al}_{2} \mathrm{O}_{3}$ (fator de correlação $r$ igual a 0,95 ) e fraca correlação negativa com o $\mathrm{Fe}_{2} \mathrm{O}_{3}, \mathrm{MgO}$ e $\mathrm{MnO}(\mathrm{r}<-0,5)$. $\mathrm{O} \mathrm{Fe}_{2} \mathrm{O}_{3}$ acompanha 0 $\mathrm{MnO}$ e ambos, juntamente com o $\mathrm{CaO}$, mostram uma correlacão negativa com o $\mathrm{MgO}$. A boa correlação entre a $\mathrm{SiO}_{2}$ e $0 \mathrm{Al}_{2} \mathrm{O}_{3}$ indica que o $\mathrm{SiO}_{2}$ aparece nas magnesitas sob forma combinada associada aos alumino-silicatos e não como fase livre. Já a fraca correlação, seja

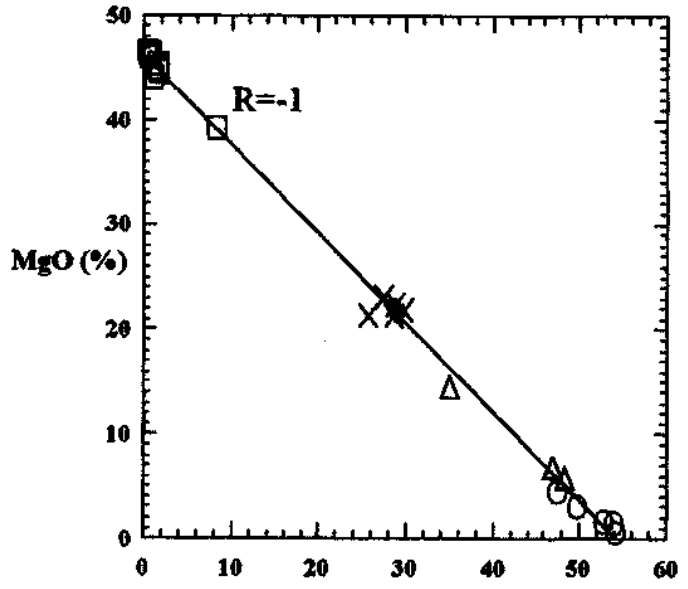

Figura 11 - Diagrama $\mathrm{MgO}$ vs $\mathrm{CaO}$ para as rochas metacarbonáticas estudadas. Símbolos como na figura 9.

positiva ou negativa, de $\mathrm{Fe}_{2} \mathrm{O}_{3}$ com $\mathrm{Al}_{2} \mathrm{O}_{3}$ e de $\mathrm{Fe}_{2} \mathrm{O}_{3}$ com $\mathrm{SiO}_{2}$ mostra que os silicatos correspondem a clorita pobre em Fe (clinocloro) ou ainda illita, conforme pode ser observado na figura 10 . Os outros elementos, como $\mathrm{P}_{2} \mathrm{O}_{5}$ e $\mathrm{TiO}_{\mathrm{s}}$ parecem não correlacionar-se com 0 $\mathrm{MgO}$, devido ao baixo fator de correlação $(r<0,3)$, vide tabela 2 .

Nos mármores dolomíticos, o $\mathrm{SiO}_{2}$ mostra uma correlacão positiva com o $\mathrm{Al}_{2} \mathrm{O}_{3}$, com o $\mathrm{Fe}_{2} \mathrm{O}_{3}$ e o $\mathrm{MgO}$ e negativa com o $\mathrm{MnO}$, embora com um fator de correlação $(r)$ bem inferior aquele encontrado junto aos mármores magnesíticos (tabela 3). $\mathrm{O} \mathrm{Fe} \mathrm{F}_{3}$ acompanha o $\mathrm{MnO}$ e ambos, junto com o $\mathrm{CaO}$, apresentam uma correlação negativa com 0 $\mathrm{MgO}$. A baixa correlação positiva entre $\mathrm{SiO}_{2}$ e $\mathrm{Al}_{2} \mathrm{O}_{3}, \mathrm{Fe}_{2} \mathrm{O}_{3}$ e $\mathrm{Al}_{2} \mathrm{O}_{3}$ e de $\mathrm{Fe}_{2} \mathrm{O}_{3}$ com $\mathrm{SiO}_{2}$ mostra que, nos mármores dolomíticos, a sílica pode ser encontrada tanto em fase livre (quartzo) quanto em mineral sílico-aluminoso. Quanto ao mineral alumino-silicático, este corresponde a uma clorita mais rica em Fe que a dos mármores magnesíticos espáticos ou ainda uma illita (Fig. 10). Em relação aos elementos $\mathrm{P}_{2} \mathrm{O}_{5}$ e $\mathrm{TiO}_{2}$, estes também não correlacionam-se com o $\mathrm{MgO}$ ( fator de correlação $r<0,2$ ).

Nos mármores calcíticos, o $\mathrm{SiO}_{2}$ mostra uma correlação positiva com o $\mathrm{Al}_{2} \mathrm{O}_{3}, 0 \mathrm{Fe}_{2} \mathrm{O}_{3}$ e $\mathrm{MgO}$ (tabela 4). $\mathrm{O} \mathrm{Fe} \mathrm{O}_{3}$ apresenta uma correlação negativa com $\mathrm{MnO}$, assim como o $\mathrm{CaO}$ versus o $\mathrm{MgO}$. A correlação positiva entre $\mathrm{Fe}_{2} \mathrm{O}_{3}$ com $\mathrm{Al}_{2} \mathrm{O}_{3}$ e de $\mathrm{Fe}_{2} \mathrm{O}_{3}$ com $\mathrm{SiO}_{2}$ mostra que o mineral silicático aluminoso associado com os calcários corresponde a uma clorita mais rica em Fe ou ainda uma illita, conforme pode ser observado na Fig. 10. Quanto aos elementos $\mathrm{P}_{2} \mathrm{O}_{5}$ e $\mathrm{TiO}_{2}$, nessas rochas, também não se correlacionam com o $\mathrm{MgO}(\mathrm{r}<\mathrm{O}, 3)$.

No geral, verifica-se que a passagem dos mármores calcíticos em direção aos mármores magnesíticos, através dos mármores dolomíticos, é marcada por grandes variações no interior dessas rochas. Ob- 
Tabela l-Análises químicas dos elementos maiores (em \%) das rochas metacarbonáticas da Faixa Móvel Orós.
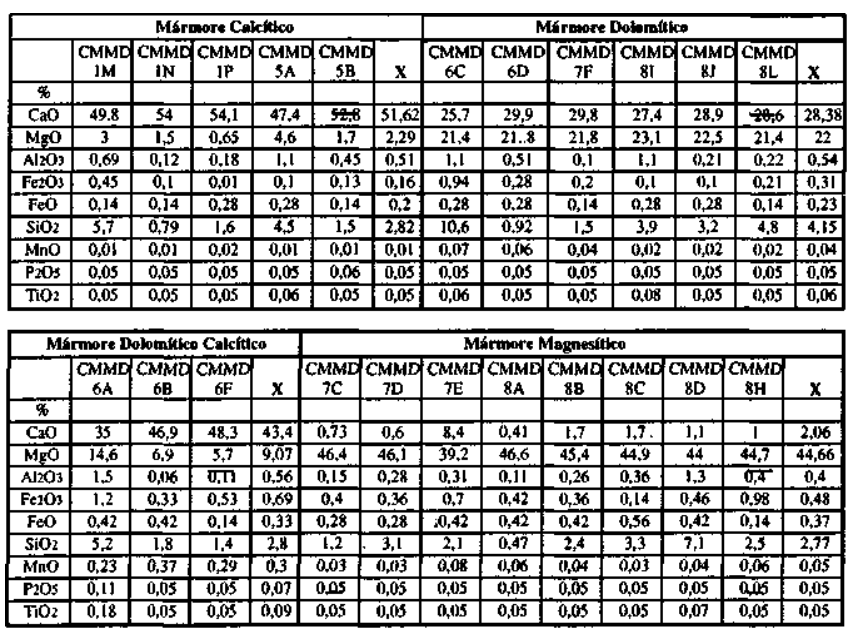

serva-se uma nítida diminuição de $\mathrm{CaO}$ dos mármores calcíticos em direção aos mármores magnesíticos espáticos (Fig. 11). No entanto, Parente (1995) observou também uma diminuição de $\mathrm{SiO}_{2}$ e $\mathrm{Al}_{2} \mathrm{O}_{3}$ indo dos metadolomitos em direção aos mármores magnesíticos. A diferença desses resultados pode refletir um menor número das amostras estudadas em relação aquele de Parente (1995) ou ainda uma menor variação dos tipos litológicos estudados por Parente (1995) (somente mármore magnesítico e dolomítico). Por outro lado, Pohl \& Siegl (1986) consideram que a diminuição desses elementos reflete um processo de diferenciação química normal, pois os dois primeiros elementos encontram-se sobretudo na fração argilosa das rochas carbonáticas, enquanto o $\mathrm{CaO}$ diminui gradativamente dos calcários em direção aos magnesititos.

Quanto aos óxidos $\mathrm{MnO}$ e $\mathrm{Fe}_{2} \mathrm{O}_{3}$, eles apresentam distribuições irregulares. $\mathrm{O} \mathrm{MnO}$ parece diminuir dos mármores calcíticos em direção aos mármores magnesíticos (Fig. 12a). Entretanto, ao excluir as três amostras correspondentes aos mármores dolomíticos calcíticos, verifica-se um enriquecimento progressivo em $\mathrm{MnO}$ dos mármores calcíticos em direção aos mármores magnesíticos (Fig. 12b). De acordo com Niedermayer et al 1989, os teores do Fe e do Mn são mais elevados em águas continentais ou meteóricas que em águas do mar Considerando que os mármores dolomíticos calcíticos representam material brechado e cimentado por calcita de substituição, esses valores anormais podem estar associados a um enriquecimento supergênico. Por outro lado, na sequência normal das rochas carbonatadas, $\mathrm{O} \mathrm{Fe}_{2} \mathrm{O}_{3}$ apresenta também uma maior irregularidade e teores mais elevados junto aos mármores magnesíticos. $\mathrm{O}$ enriquecimento do $\mathrm{Fe}_{2} \mathrm{O}_{3}$ e do $\mathrm{MnO}$ junto aos termos magnesíticos pode estar associado ao caráter mais solúvel dos ions de $\mathrm{Mn}$ e $\mathrm{Fe}$ no ambiente alcalino, o que os leva a precipitarem-se junto ao $\mathrm{MgO}$ nas fases mais diferenciadas da sequência carbonatada.

Assim, o Mn varia em função da evolução do Eh e pH. Em condições de Eh e $\mathrm{pH}$ próximo ao valor neutro, o íon Mn 2+ resta em solução e está disponível para precipitar como componente do carbonato (Garreis \& Christ 1965 in Niedermayer et al. 1989). O conteúdo de MnO dos calcários é inferior aquele dos dolomitos (Holland 1984). Isso sugere que o $\mathrm{Mn}$ pode ser mais solúvel que o $\mathrm{Ca}$ e, como tal, deve ficar em solução e precipitar com o $\mathrm{MgO}$, independentemente de mobilizações tardias localizadas. Contudo o $\mathrm{Fe}$ e o $\mathrm{Mn}$ das rochas carbonáticas são susceptíveis de mobilizações tardias, sejam elas associadas à diagênese ou ao metamorfismo. Por outro lado, tais rochas se desenvolveram provavelmente no final do Paleoproterozóico e início do Mesoproterozóico. Nesse período, o comportamento do Fe e do Mn era diferente do atual. Nesse sentido, os carbonatos do Paleoproterozóico $(2,25 \pm 0,25 \mathrm{Ga})$ eram muito mais enriquecidos em $\mathrm{Fe}$ e Mn que seus homólogos fanerozóicos (Veizer et al. 1992).

As variações químicas e a dispersão irregular desses elementos ao seio das rochas carbonáticas sugerem também que a sedimentação ocorreu em condições ambientais variáveis de baixa profundidade. A presença de pelo menos 4 níveis delgados de metapelitos intercalados ao seio dos metadolomitos, encontrados por Parente (1995), constitui um argumento complementar.

Assim, através do estudo geológico e geoquímico dos elementos maiores pode-se dizer, em princípio que: 1 - a presença de delgados
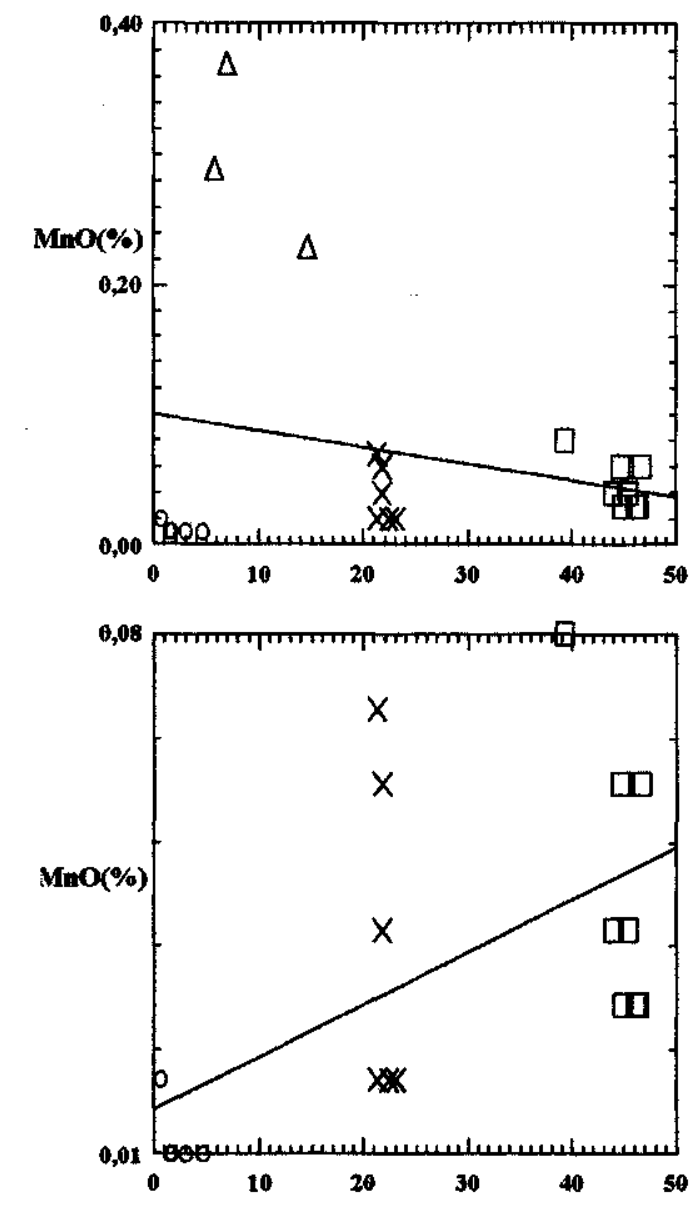

Figura 12 - Diagramas $\mathrm{MnO}$ vs $\mathrm{MgO}$ para as rochas metacarbonáticas estudadas. Símbolos como na figura 9.

níveis de metapelitos no seio dos metadolomitos, sobretudo nas proximidades do contato com os metapelitos, traduz a intervenção de processos de sedimentação escalonados, ligados às variações sazonais ou climáticas (alternâncias de estações úmidas e secas) com movimentos de subsidência da bacia ou elevação do nível do mar acompanhado de aporte de sedimentos detríticos, 2- a presença de brechas de dissolução com nódulos de sulfatos pseudomorfizados por quartzo fibrosos indica que condições evaporíticas reinaram, ao menos localmente, durante a deposição dos carbonatos; 3- a formação das magnesita espática ocorreu de maneira mais uniforme, em um ambiente mais homogéneo ou mais calmo, e os calcários em ambiente marinho mais aberto.

Em relação aos mármores magnesíticos de grão médio, Parente (1995) observou que tais rochas apresentam uma composição mais irregular e os teores de $\mathrm{SiO}_{2}, \mathrm{Al}_{2} \mathrm{O}_{3}, \mathrm{Fe}_{2} \mathrm{O}_{3}$ e $\mathrm{CaO}$ são maiores que em seus correspondentes espáticos. De acordo com este autor, o $\mathrm{SiO}_{2}$ varia de 1,1 a21,9 com um teor médio de 7,19, $\mathrm{Al}_{2} \mathrm{O}_{3}$ variando de $\mathrm{O}, 1$ a $4,5 \%$ com um teor médio de $0,76 \%, \mathrm{o} \mathrm{Fe}_{2} \mathrm{O}_{3}$ indo de 1,5 a 4,5 com um teor médio de $2,4 \%$, o $\mathrm{CaO}$ oscilando entre 0,8 a 10,1 e um teor médio de $2,29 \%$ e $\mathrm{MgO}$ indo de 75 a $95 \%$ com um teor médio de $87,15 \%$.

Comparando-se os dois tipos de mármores magnesíticos, verificase que os mármores magnesíticos espáticos são mais ricos em $\mathrm{MgO}$ e mais pobres em $\mathrm{SiO}_{2}, \mathrm{Al}_{2} \mathrm{O}_{3}, \mathrm{Fe}_{2} \mathrm{O}_{3}$ e $\mathrm{CaO}$ que os mármores magnesíticos de grão médio. A distribuição desses elementos junto aos magnesititos é também diferente. Nos mármores magnesíticos de grão médio, eles apresentam uma distribuição mais irregular, enquanto nos mármores magnesíticos espáticos, eles são mais regulares.

De igual modo, os mármores magnesíticos espáticos se diferenciam dos metadolomitos. Estes são mais ricos em $\mathrm{SiO}_{2}, \mathrm{Al}_{2} \mathrm{O}_{3}$ e $\mathrm{CaO}$ e, em proporção mais fraca, em $\mathrm{MnO}$ que os mármores magnesíticos espáticos, enquanto os mármores magnesíticos espáticos são mais ricos que os metadolomitos em $\mathrm{MgO}$ e, em uma proporção menor, em $\mathrm{Fe}_{2} \mathrm{O}_{3}$. 
MODELO GENÉTICO Um dos grandes problemas no estudo dos depósitos de magnesita associado com rochas metamórficas de origem sedimentar é sua origem, seja sedimentar, seja metassomática.

A maioria dos autores que admitem a origem metassomática apoiase nos argumentos morfológicos ou mineralógicos seguintes: 1- observa-se, ao nível de amostra ou mesmo de afloramento, substituições mais ou menos tardias de dolomita por magnesita - mas o inverso é mais frequente; 2- a producão experimental da magnesita em condições de $\mathrm{T}<50^{\circ} \mathrm{C}$ jamais foi obtida. Em compensação, é bastante fácil formá-la em temperaturas mais altas $\left(120\right.$ à $\left.450^{\circ} \mathrm{C}\right)$, como confirmado pelos estudos experimentais de Rosenberg \& Mills (1966) e Johannes (1970 in Morteani et al. 1982,1983), 3- os depósitos e/ou ocorrências de magnesita naturais atuais, sedimentares ou não, são de pequena extensão, para serem representativos de formação dos grandes jazimentos do passado. Entretanto, o simples fato de sua existência, coloca em discussão 0 argumento precedente; 4- a granulometria das magnesitas espáticas é frequentemente mais grossa que aquelas dos dolomitos, o que sugeriria uma substituição. Todavia existem dolomitos espáticos, intercalados entre magnesititos e dolomitos mais finos, pelo menos em alguns jazimentos (Montner-França, Guitard in Guillou 1980, Pacios-Espanha, Guillou 1980); 5- o tipo de magnesita associado às formações evaporíticas apresenta frequentemente uma granulometria média à fina. As magnesitas espáticas, até à realização do trabalho de Parente (1995), não tinham sido encontradas em associação franca com os depósitos evaporíticos; 6- na natureza atual, a precipitação dos carbonatos magnesianos faz-se preferencialmente sob a forma de carbonatos metaestáveis (hidromagnesita, nesquehonita) e não sob forma de magnesita.

Esses argumentos metassomáticos, apesar de numerosos, são contraditórios e pouco convincentes. Para uma melhor compreensão, iremos discuti-los e compará-los com os dados recolhidos sobre os jazimentos estudados.

$\mathrm{O}$ exame do diagrama Temperatura vs Razão $\mathrm{Ca}^{2+} /\left(\mathrm{Ca}^{2+}+\mathrm{Mg}^{2+}\right)$ de Rosenberg \& Mills (1966) permite colocar os termos do problema de várias maneiras: primeira em função das variações de $\mathrm{T}^{\circ}$ em relação com as fontes magnesianas profundas : a) se $\mathrm{T}^{\circ}$ aumenta, a formação da magnesita torna-se em teoria fácil. De fato, sabe-se que este carbonato é um mineral raríssimo nos filões hidrotermais. Em tais ambientes, há sempre bastante cálcio disponível para formar dolomita. Como $0 \mathrm{Fe}^{++}$é igualmente presente, haverá a formação de dolomita ferrífera ou ankerita. Enfim, quando o $\mathrm{Ca}$ é comum, a associação do $\mathrm{Fe}$ e $\mathrm{Mg}$ forma uma série continua de carbonatos intermediários, a série das mesistitas ( $\mathrm{Mg}-\mathrm{Fe}) \mathrm{CO}_{3}$. Assim, a magnesita hidrotermal aparece somente em circunstâncias excepcionais, particularmente quando corpos ultrabásicos são afetados por estruturas tectônicas profundas, tipo zona de cisalhamento; b) sabe-se já que os magmas ultrabásicos e básicos não geram fluidos hidrotermais em circunstâncias normais. Ao contrário, as rochas básicas fixam água das encaixantes e se hidratam (serpentinização e esteatização).

Assim, pode-se dizer que as rochas básicas que se encontram em contato com os magnesititos espáticos, inclusive porque cortam tais rochas, não contribuíram para a formação dos grandes corpos de magnesita estudados, como foi sugerido por alguns autores, entre eles, Bodenlos (1948) e Mendonça \& Braga (1987). Além disso, trabalho em desenvolvimento com colegas da Universidade da UNISINOS (Prof. Luís Henrique Ronchi) sobre inclusões em magnesitas da região de Alencar e adjacências, tem revelado a presença de petróleo, fato que elimina totalmente a hipótese hidrotermal como processo formador dessas rochas. Entretanto, fenómenos de remobilização tardia podem ser observados, como a presença de pequenos veios de magnesita que recortam os metadolomitos, os quais podem estar associados ao período de intrusão das rochas básicas. Tais veios estariam relacionados às modificações de temperatura e às circulações provocadas por ocasião do metamorfísmo de contato, sem envolver um aporte aloquímico do $\mathrm{Mg}$.

E mais construtivo, portanto, optar por um mecanismo precoce, isto é, sedimentar, tendo como base a evolução da razão $\mathrm{Ca}^{2}+/\left(\mathrm{Ca}^{2+}+\right.$ $\left.\mathrm{Mg}^{2+}\right)$. A maioria dos trabalhos sobre a formação de magnesita em ambientes sedimentares recentes, tem mostrado que esta razão diminui nas rochas carbonáticas dos sistemas parálicos, indo do mar aberto para 0 interior. Nesse sentido, vai-se dos termos cálcicos de mar aberto aos termos magnesianos de ambiente confinado. A diminuição de $\mathrm{Ca}^{2+}$ pode estar relacionada seja à cristalização inicial dos carbonatos cálcicos, seja à cristalização de sulfates ou aos dois (Müller et al. 7972, Von der Borg 1965, 1976).

Nos ambientes mais antigos, esta diferenciação já foi demonstrada por Guillou (1980) no Cambriano espanhol (Pacios e Mallecina), cuja
Tabela 2 - Matriz de correlação dos mármores magnesíticos.

\begin{tabular}{|c|c|c|c|c|c|c|c|c|c|}
\hline & $\mathrm{C} 3 \mathrm{O}$ & $\mathrm{M}_{8} \mathrm{O}$ & $\mathrm{Al}_{2}, \mathrm{O}_{3}$ & $\mathrm{Fe}_{2} \mathrm{O}_{3}$ & $\mathrm{FeO}$ & $\mathrm{SiO}_{3}$ & $\mathrm{MnO}$ & $\mathrm{P}_{3} \mathrm{O}_{3}$ & $\mathrm{TiO}_{2}$ \\
\hline $\mathrm{TiO}_{2}$ & $-0,15$ & $-0,11$ & 0,97 & $-0,03$ & 0,17 & 0,88 & $-0,14$ & 0 & \\
\hline $\mathrm{P}_{2} \mathrm{O}_{3}$ & 0 & 0 & 0 & 0 & 0 & 0 & 0 & & \\
\hline $\mathrm{MnO}$ & 0,73 & $-0,69$ & $-0,1$ & 0,7 & 0,09 & 0,28 & & & \\
\hline $\mathrm{SiO}_{2}$ & $-0,08$ & $-0,18$ & 0,95 & $-0,08$ & 0,18 & & & & \\
\hline $\mathrm{FeO}$ & 0,17 & $-0,2$ & 0,13 & $-0,7$ & & & & & \\
\hline $\mathrm{Fe}_{2} \mathrm{O}_{3}$ & $\mathbf{0 , 3 9}$ & $-0,42$ & 0,07 & & & & & & \\
\hline $\mathrm{Al}_{2} \mathrm{O}_{3}$ & $-0,06$ & $-0,22$ & & & & & & & \\
\hline $\mathrm{MgO}_{3} \mathrm{O}$ & $-0,96$ & & & & & & & & \\
\hline
\end{tabular}

Tabela 3 - Matriz de correlação dos mármores dolomíticos.

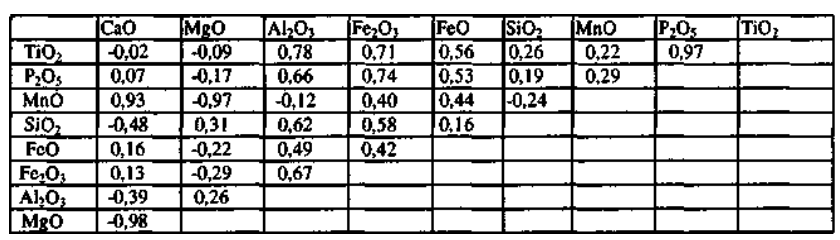

Tabela 4 - Matriz de correlação dos mármores calcíticos.

\begin{tabular}{|c|c|c|c|c|c|c|c|c|c|}
\hline & $\mathrm{CaO}$ & M8O & $A \mid 203$ & $1 F e 203$ & $F \in 0$ & $\mathrm{SiO} 2$ & $\mathrm{MnO}$ & P205 & TiO02 \\
\hline Ti02 & $-0,81$ & 0,84 & 0,82 & $-0,19$ & $\overline{0,61}$ & 0,44 & $-0,25$ & 0,34 & \\
\hline P205 & $-0,25$ & 0,28 & 0,40 & $-0,20$ & $=0,04$ & $-0,08$ & 4.39 & & \\
\hline $\mathrm{MAO}$ & 0,47 & $-0,59$ & $-0,46$ & $-0,49$ & 0,61 & $-0,32$ & & & \\
\hline $\mathrm{SiO2}$ & $-0,86$ & 0.78 & 0,81 & 0,74 & 0,10 & & & & \\
\hline$F \subset \bar{O}$ & $-0,27$ & 0,20 & 0,30 & $-0,56$ & & & & & \\
\hline 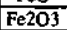 & $-0,42$ & 0,36 & 0,34 & & & & & & \\
\hline Al203 & $-0,98$ & 0,96 & & & & & & & \\
\hline MgO & $-0,98$ & & & & & & & & \\
\hline
\end{tabular}

sequência, dominada por calcários, dolomitos e magnesititos, desenvolvia-se progressivamente do mar aberto para o ambiente lagunar. Neste trabalho, encontramos uma das alternativa propostas por Guillou (1980), isto é, os magnesititos encontram-se em posição umbilical na paleolaguna e não em posição marginal como no Cambriano espanhol. Guillou (1980) propõe também associar a diminuição histórica de $\mathrm{fCO}_{2}$ atmosférico pela ação dos organismos fixadores de carbono à causa da diminuição e depois ao desaparecimento das magnesitas espáticas: esta diminuição de $\mathrm{CO}_{2}$ é atualmente aceita por unanimidade. Pode-se pensar ainda na solubilidade do $\mathrm{Ca}$, que em comparação com a do $\mathrm{Mg}$, aumenta com a elevação da $p \mathrm{CO}_{2}$.

Um outro ponto a ser assinalado é o de que os carbonatos hipermagnesianos são mais resistentes que seus homólogos cálcicos tanto às deformações tectônicas quanto à dissolução sob pressão. Submetidos à deformação e ao metamorfísmo eles resistem melhor às trocas iônicas que os carbonatos cálcicos. Assim, na hipótese metassomática com deformação e aporte hidrotermal, a magnesita e seu precursor dolomítico teriam uma assinatura similar em elementos traços pouco móveis como o Al. Ora, os mármores magnesíticos espáticos e os metadolomitos encaixantes apresentam diferenças importantes em $\mathrm{Al}_{2} \mathrm{O}_{3}$ sem falar de $\mathrm{SiO}_{2}, \mathrm{Fe}_{2} \mathrm{O}_{3}$ e $\mathrm{MnO}$. Assim, a hipótese metassomática, em grande escala, não combina com os fatos. Todavia, diferenças dessa natureza podem corresponder a fenómenos sedimentares simples, tais como depuração progressiva das águas lagunares em arguas $\left(\mathrm{Al}_{2} \mathrm{O}_{3}\right.$ e $\left.\mathrm{SiO}_{2}\right)$ e, ao contrário, seu enriquecimento $\mathrm{em} \mathrm{Fe}^{2+}$, muito estável nas águas na época de formação dessas rochas. Além disso, se é considerado o detalhe das condições hidroló gicas, três outros argumentos contraditórios estão presentes: a) a presença frequente de mármores dolomíticos e de mármores magnesíticos ferríferos, assim como grãos de zircão detríticos ao seio dos metadolomitos encaixantes; b) a presença de brechas vermelhas de dissolução (dissolucão de evaporitos), com lutecita, nódulos de sulfatos pseudomorfizados por quartzo fibrorradiado situado no contato de metadolomitos e de magnesititos, assim como a presença frequente de escapolita que indicam também condições evaporíticas. Nesse caso, a fração salina precoce teria sido parcialmente dissolvida durante a fase de emersão em condições oxidantes, pois ainda são encontrados alguns nódulos de sulfatos pseudomorfizados; c) enfim, as brechas de dissolução e delgados níveis de metapelitos no interior dos metadolomitos sugerem um hiato na sedimentação carbonática.

Do exposto verifica-se que os magnesititos estudados encontram-se em borda de uma zona em fase de emersão, submetida a pronunciada alteração, porém erosão reduzida, sob condições climáticas indo de úmida à árida. Sabe-se ainda, que em clima úmido, aportes aluminosos e detríticos evoluídos caracterizam o contexto sedimentar em geral. Pode-se pensar portanto, na existência, pelo menos na época de formação das magnesitas, de aportes episódicos de água doce continental trazendo o ferro e minerais pesados. Já os dolomitos localizam-se mais precisamente nas grandes depressões (lagunas) parálicas, intra-deltái- 


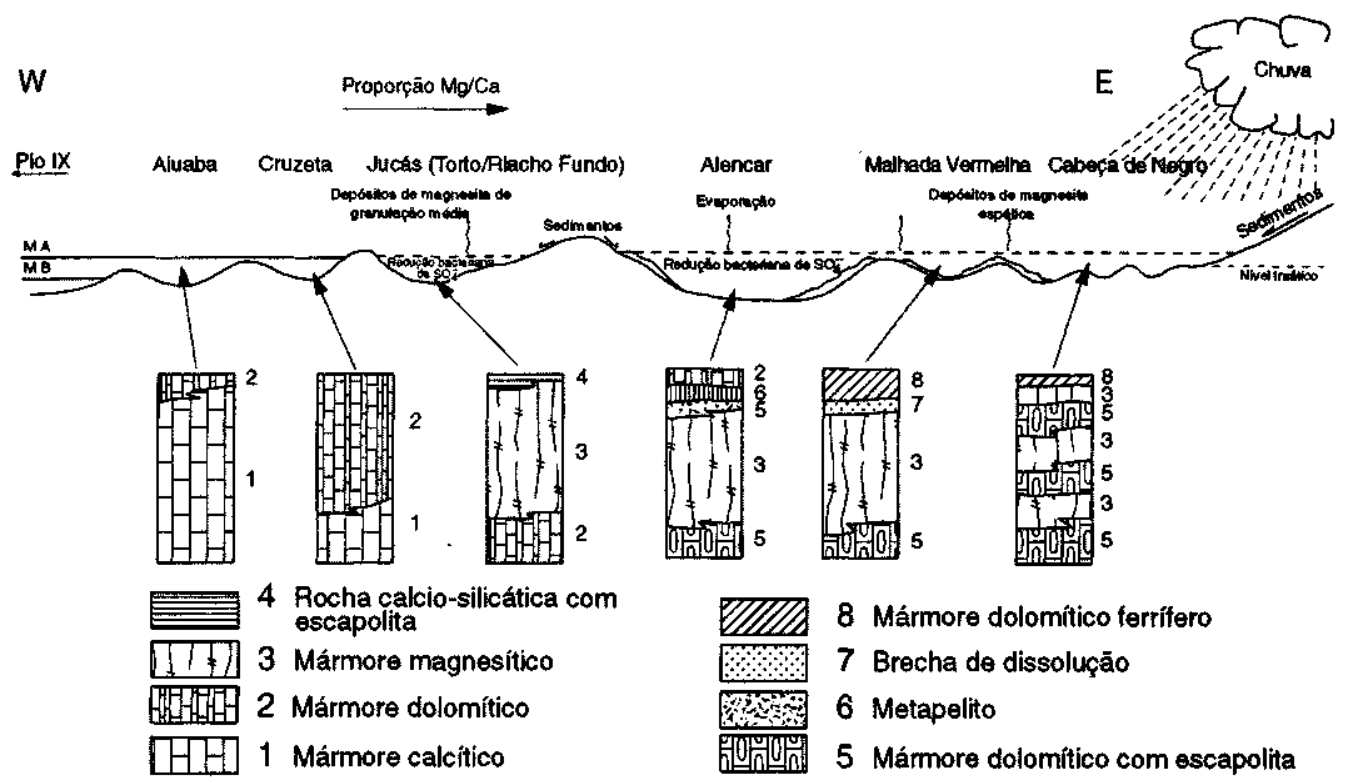

Figura 13 - Esquema interpretativo da sequência carbonatada magnesítica do Ceará, Brasil. Para efeitos de comparação foram representadas as sequências carbonatadas de Aiuába e Cruzeta.

cãs. Os calcários são mais distais e corresponderiam a ambientes mais abertos, marinhos. No todo, esses carbonatos aparecem durante períodos de fraca erosão, sob clima árido. Os indícios de evaporitos se integram bem no contexto. Além disso, o aparecimento de ocorrência de matéria orgânica, em particular petróleo, sugere uma atividade biológica em meio confinado.

Quanto aos aspectos ligados às variações de granulometria, a presença de dois tipos de magnesita de granulometria diferente, na região estudada, evidencia um problema interessante. Sabe-se, em geral, que a granulometria dos sedimentos carbonáticos é frequentemente ligada à concentração dos íons e à salinidade do ambiente de formação (cf. Folk \& Land 1975, Guillou 1980). Dois processos são comuns: a co-precipitação e a maturação do precipitado.

A co-preciptação é uma precipitação química ligada à presença de impurezas. Estas impurezas podem ser adsorvidas ou ocultadas na estrutura do mineral hospedeiro durante a fase de cristalização. Este processo acontece em ambiente supersaturado rico em impurezas, onde a cristalização é rápida (Catani et al. 1970 in Almeida 1989). Assim, em um ambiente evaporítico fortemente saturado, os germes são numerosos, a cristalização rápida e os sedimentos evoluirão pouco, conservando um grão fino. Folk \& Land (1975) mostraram que a formação de dolomita ordenada é inibida ao mesmo tempo pela rapidez do processo de cristalização em meio supersaturado e pela concentração de íons estranhos a este processo.

A maturação do precipitado, por sua vez, está ligada à solucão mais diluída, fracamente supersaturada, em que os germes são mais raros. Os íons estranhos, em razão de seu maior tempo de permanência em solucão, são eliminados, restando apenas os íons dominantes (Catan et al 1970 in Almeida 1989). A velocidade de cristalização dos cristais é lenta e a evolução dos sedimentos é maior. Isso permite que a formação dos cristais seja maior e mais bela (Guillou 1980). Nesse mesmo sentido, Folk \& Land (1975) mostraram que na zona de mistura de água marinha e doce (zona schizohalina) ou de salinidade mais reduzida, os cristais de dolomita são maiores e mais límpidos que aqueles que se formam em um ambiente supersaturado.

Pode-se, portanto, supor que os dois tipos de magnesita estudados desenvolveram-se em ambientes com índice de confinamento ou de salinidade diferentes: - os mármores magnesíticos de grão médio teriam se formados em um ambiente mais confinado e/ou saturado que os mármores magnesíticos espáticos. Parente (1995) constatou que os magnesíticos de grão médio são mais impuros, sendo mais ricas nos óxidos $\mathrm{SiO}_{2}, \mathrm{Al}_{2} \mathrm{O}_{3}, \mathrm{CaO}$ e em $\mathrm{Fe}_{2} \mathrm{O}_{3}$. A abundância desses óxidos inibiria a cristalização da magnesita, em um ambiente já saturado em íons magnesianos. Pode-se pensar ainda que a influếncia de águas doces foi muito fraca para modificar a salinidade do ambiente; - já os mármores magnesíticos espáticos teriam se desenvolvidos em um ambiente parálico lagunar, globalmente menos saturado que o precedente, em que a concentração dos íons seria próxima àquela do mar, tendo em conta o balanço da evaporação e a influência dos aportes de água doce. $\mathrm{O}$ ambiente seria mais límpido e mais pobre em impurezas traduzidas pela menor presença dos óxidos $\mathrm{SiO}_{2}, \mathrm{Al}_{2} \mathrm{O}_{3}, \mathrm{CaO}$ e $\mathrm{Fe}_{2} \mathrm{O}_{3}$ Isso permitiu uma cristalização mais lenta dos carbonatos, acompanhada de importantes processos diagenéticos responsáveis pela evolução cristalográfica. De acordo com Guillou (1980) e Parente (1995), é preciso considerar que as magnesitas espátícas se desenvolveram em um ambiente confinado, em que a salinidade não era muito elevada em relação a água do mar. Em um ambiente confinado, para que a salinidade possa permanecer próxima daquela do mar, é preciso uma ligação permanente com o mar e/ou aportes de águas doce continental.

No geral, os argumentos favoráveis à hipótese sedimentar parecem muito mais explicativos que a hipótese metassomática. Esta ultima é de difícil aplicação nas diferentes escalas consideradas, enquadrandose mal com os fatos e não explica as variações de granulometria encontradas nos magnesititos estudados e desenvolvidos em ambientes relativamente próximos.

Finalmente, considerando que o conjunto dos jazimentos de magnesita encontra-se em passagem lateral, para Oeste, para mármore calcítico quase puros, por intermédio dos metadolomitos, pode-se utilizar o modelo de diferenciação química proposto por Guillou (1971, $1980)$ e Chayé d'Albissin \& Guillou $(1986,1988)$, em que as magnesitas espáticas apareciam no fim da cadeia carbonatada. Tal modelo se desenvolve em uma paleografia litoral, em que as águas lagunares perdem progressivamente $\mathrm{O} \mathrm{Ca}$ por precipitação preferencial de carbonatos cálcicos, o que eleva a razão $\mathrm{Mg} / \mathrm{Ca}$ e permite a evolução dos depósitos carbonáticos até ao pólo magnesiano. A figura 13 sintetiza a evolução da sequência carbonática magnesiana estudada.

CONCLUSÃO O estudo geológico e geoquímico da sequência metacarbonática magnesiana da Faixa Móvel Orós mostra a existência de dois tipos de magnesita (espática e de granulação média) inteiramente diferentes, cuja origem é dominantemente sedimentar.

As variações de textura e de composição no domínio da magnesita indicam que tais rochas se desenvolveram em ambientes diferentes. A magnesita espática teria se formado em um ambiente parálico, fracamente saturado, em que os germes seriam raros, a cristalizacão lenta e a evolução diagenética mais importante. Já a magnesita de grão médio se desenvolveria no mesmo ambiente parálico, mas sem dúvida, mais confinado e/ou mais saturado que aquele das magnesitas espáticas. A maior concentração de íons de composição diferente associados aos ions magnesianos favoreceriam uma cristalização rápida e uma evolução diagenética menor.

Pode-se reconstituir uma paleogeografia, provavelmente diacrônica, apresentando uma série de golfos parálicos em que se misturam associações evaporíticas com influências continentais. Neste esquema, os depósitos de magnesita parecem se situar no centro de dois golfos parálicos principais, todos os dois em posição distai em relação ao mar. No maior e mais distai, encontram-se os depósitos de magnesita 
espática que se desenvolvem em um ambiente mais estável que aquele das magnesitas de grão médio.

O esquema apresentado confirma as grandes linhas de casos analisados anteriormente, sobretudo quanto à segregação do $\mathrm{Ca}$ e do $\mathrm{Mg}$ em um gradiente Mar-Continente (ou de confinamento), precisa e modifica os dados já existentes sobre a formação de outros depósitos de magnesita, e sublinha a originalidade do domínio supergênico na formação de depósitos evaporíticos e carbonáticos no Proterozóico, marcado por uma forte $\mathrm{p}_{2}$.

Agradecimentos Os autores, em particular C.V.P., agradecem à IBAR Mineração e à FUNCAP (proc. 110/95) pelo apoio aos trabalhos de campo e análises de laboratório, e aos revisores anónimos da RBG pelas sugestões e críticas ao manuscrito.

\section{Referências}

Aharon, P. 1988. A stable-isotope study of magnesitcs from the Rum Junglc Uranium Field, Australia: implications for the origin of strata-bound massive magnesites. Chemical Geology, 69:127-145.

Almeida, T.I.R. 1989. Magnesita do depósito de Campo de Dentro, Serra das Éguas, Bahia: Geoquímica e gênese. Tese de doutoramento da Universidade de São Paulo. Instituto de Geociências (inédite).173p.

Anfimov, L.V.; Busygin, B.D.; Demina, L.E. 1980. Formation conditions of magnesites in the Satka Group of ore deposits, South Urais. Lithology Mineralogy Ressources (USSR), 15:93-103.

Arbey, F. 1980. Les formes de Ia silicc et l'identification des évaporites dans les formations silicifiées. Bull. des Centres de Rech. ExpL-Prod. Elf-Aquitaine, 4 (1):309-365.

Arnold, M. \& Guillou, J.J. 1983. Croissance naturcllc de paracristaux de quartz dans une saumurc sulfatée calcique à basse tempéralure. Bull. Minera, 106:417-442.

Badham, J.P.N. \& Stanworth, C.W. 1977. Évaporites from the lower Prolerozoic of the East Arm, Great Slave Lake. Nature, 268 (1 1):516-518.

Bodenlos, A.J. 1948. Magnesite deposits of Ceara Bnaü.U.S.Geological Survey Bulletin 062-C: $121-151$

Bodenlos, A.J. 1954. Magnesite deposits in the Serra das Éguas, Brumado, Bahia, Brazil. U.S.Geological Survey Bulletin, 975L:87-170.

Bone, Y. 1983. Interpretation of magnesites at Rum Jungle, N.T., using fluid inclusions. Journal Of the Geológica] Soe. Austrália, 30:375-381.

Brunel, M.; Chaye d'Albissin, M.; Locqui, M. 1984. Détermination d'un age cambrien des séries carbonatées à magnésite situées sous le grand chevauchement himalaycn (Main Central Thrust, Nepal oriental) par Ia découverte de Paléobasidispores. Geohios, Lyon, 17:595-602.

Busson, G \& Perthuisot, J.P. 1977. Intérêt de Ia Sebkha El Melah (sud-Tunisien) pour 1'interprétation des séries évaporitiques anciennes. Sedimentary Geology, 19:139-164.

Chaye d'Albissin, M. \& Guillou, J.J. 1985. La conservation de microorganismos dans une manésitite spathique et ses incidenccs crislallogénétiques et sédimentologiques. C.R Acad. Sc. Paris, t.301, série II, (11):797-799.

Chaye d'Albissin, M. \& Guillou, J.J. 1986. Evolution cristallogénétique de magnésiles spathiques antéjurassiques, du stade sédimenlaire à Ia mésozone. Exemples compares de Gumpa-de-Bigu (Nepal) et de Pacios (Espagne). Revue de Géologie Dynamique et de Géographie Physique, 27(5):339-349.

Chaye d'Albissin, M. \& Guillou, J.J. 1988. Conditions de gênese et comportement mécanique des magnesites spathiques antéjurassiques au cours de leur histoirc géologique. Bull. Soe. Géol France; t.IV, n_5, 871-877.

Chaye d'Albissin, M.; Guillou, J.J.; Letoller, R. 1988. Observation on the paper by F.Vclasco et al,: A contribution to the ore gênesis ofthe magnésite deposit of Eugui, Navarra (Spain). Mineral Deposita, 23:309-312

Doval, M.; Brell, M.; Galan, E. 1977. El yacimento de magnesita de Incio (Lugo, Espana). Boi. Geol. Minero, 88(1):50-64

Folk, R.L. \& Land, L. S. 1975. Mg/Ca Ratio and Salinity: two conlrols over crystallization of dolomite. Am. Ass. Petrol. Geol. Bulletin, 59(1):60-68.

Forbes, B.G. 1961. Magnesite ofthe Adelaide System: A discussion of its origin. Trans. Roy. Soe. S. Aust. 85:217-222.

Friedman, G.M. 1980. Dolomite is an cvaporitc mineral : Evidence from the rock and from sca-marginal ponds of Red Sea, in Conccpts and Modcls of Dolomitization (cds: Zengcr, D.H.; Dunham, J.B.; Ethington, R.L): Soe. Econ. Palcontologists Mincralogisls Spec. Pub. N . 28.

Friedman, G. M. \& Shukla, V. 1980. Significance of authigenic quartz. euhedra after sulfates : example from the Lockporth Formation (Middlc Silurian ) of New York. Jour. Sedimentary Petrology, 50(4): 1299-1304

Frost, M.T. 1982. The magnésite deposit at Main Crcck, Savagc Ri ver, Tasmania. Economic Geology, 77:1901-1911.

Gomez de Llarena, J.G. 1968. La diagénesis en Ia dolomita y magnesita de Asturrcta (Eugui, Navarra): un problema por estudiar. Boi R. Soe. Espanola Hist. Nat. (Geol,), 66: 41-48.

Guillou, J.J. 1972. La série carbonatée magnésicnnc et l'évolution de Ia composition de 1 'hydrosphère. C. R. Ac. Sc. Paris 274:2952-2955.

Guillou, J.J. 1973. Les concentrations magnésiennes silicatécs en contexte métamorphiquc: apport métasomatique ou préexistencc ? C. R. Ac. Sc. Paris 276:149-151

Guillou, J.J. 1980. Contribution à Ia métallogénie dês magnésilitcs, exemple du Cambricn Espagnol. Thèse de Doctorat d'Etat de 1'Université Pierrc et Maric Curic (Paris 6).155p.

Guillou, J.J. \& Letolle, R. 1988. Origine mixte chimique et biochimique des dépôts de magnésite antérieurs au Jurassique en milieu marin confine, marginal-littoral. C.R. Acad. Sc. Paris, t. 303, Série II, n 3, 207-212.

Hall, S. M.\& Veizer, J. 1996. Gcochemistry of Prccambrian carbonates: VII. Belt supcrgroup, Montana and Idaho, USA. Geochimica et Cosmochimica Acta. 60(4):667-677

Hietanen, A. 1967. Scapolite in the Belt Series in the St. Joc-Clearwater Region, Idaho. Geol.Soc. Amer. Spec. Paper. 86:1-56.

Hogarth \& Griffm. 1978. Lápis lazuli from Baffin Island: a Prccambrian mctacvaporitc. Lithos 11:37-60

Holland, H. D. 1984. The chemical evolution of the atmosphere and oceans. Ed. Princcton University Press, Princeton, N.J. 582p.

Kralik, M.; Aharon, P.; Schroll, E.; Zachamnn, D. 1989. Carbon and oxygen isotopc syslematics of magnesites: a review. Monograph Series Mineral Deposits.2\&: 197-223.

Leake, B. E. \& Farrow, C.M. 1979. A pre-2000 My old granulitc facies metamorphosed evaporite from Caraiba, Brazil ? Nature, 277(4):49-50

Mendonça, J.C.G. S. \& Braga, A.P.G. 1987. As faixas vulcano-sedimentares de Orós-Jaguaribe: um greenstone belt? Revista Brasileira de Geociências; 17(3):225-241

Möller, P. 1989. Minor and trace elcments in magnésite. Monograph Series Mineral Deposits.28:173-195.

Morteani, G. 1989. Mg-metasomatic typc sparry magnesitcs of Entachen Alm, Hochfilzen/Bürglkopf and Spiessnägel (Austria). Monograph Series Mineral
Morteani, G.; Möller, P.; Schlcy, F. 1982. The Rare Earth Element contents and the origin of the sparry magnesite mineralizations of Tux-Lanersbach, Entachen Alm, Spiessnägel, and Hochfilzen, Austria, and the lacustrine magnesite deposits of Aiani-Kozani, Greece, and Bela Stcna, Yugoslavia. Economic Geology, 77:617-631.

Morteani, G.; Schely, F.; Möller, P. 1983. On the formation of magnesite. In: Mineral Deposits of the Alps and of the Alpine Epoch in Europe (ed. H.J. Schneider). Springer-V. Berlin Heidclberg; 105-116.

Müller, G.; Irion, G.; Forstner, U. 1972. Formation and diagenesis of inorganic Ca-Mg Carbonates in the Lacustrine Environment. Natunvissencltaften, 59(4): 158-164.

Niedermayer, G.; Beran, A.; Brandstatter, F. 1989. Diagenetic type magnesites in the Permo-Scythian rocks of the Eastern Alps, Austria. Monograph Series Mineral Deposits.28:35-59

Nishihara, H. 1956. Origin of the bedded magnesite deposits of Manchuria. Economic Geology, 41:698-711.

Papaioanou, F.P \& Carotsieris, Z. 1993. Dolomitization patterns in Jurassic-Cretaceous dissolution -collapse breccias of Mainalon Montain (Tripolis Unit, Central Peloponnesus - Grcccc). Carbonates and Evaporites, 8(1):9-22.

Parente, C.V. 1995. Géologie et paléogégraphie d'une plate-forme à évaporites et magnésite d'âge protérozoique (2 Ga): le cadre géotectonique initial de Ia ceinture mobile Orós dans Ia région d'Alencar (Ceará-Brésil). Thèse de Doctorat de 1'Univcrsité de Nantes. dans Ia région

Parente, C. V. \& Arlhaud, M. H. 1995.0 Sistema Orós-Jaguaribe no Ceará-NE do Brasil. Revista Brasileira de Geociências, 25(4):297-305

Parente, C.V.; Guillou, J.J.; Barbosa, H. S. 1996. Evaporitos pré-cambrianos ( 1,8Ga) da Faixa Orós, Ceará (Brasil). Revista de Geologia, 9:5-16.

Pcrry Jr., E.C. \& Tan, F.C. 1972. Significance of Oxygen and Carbon Isotope variations in Early Precambrian Cherts and Carbonate Rocks of Southem Africa. Geol, Soe. Am. Buli. 83, 647-664.

Pohl, W. 1989. Comparative geology of magnesite deposits and occurences. Monograph Series Mineral Deposits. (Ed. Möller, P.). 28:1-13.

Pohl, W. 1990. Genesis of magnesite deposits: models and trends. Geologische Rundschau, 79(2):291-299.

Pohl, W. \& Sicgl, W. 1986. Scdiment-hosted magnesite deposits. In: Handbook of strata-bound and stratiform ore deposits (ed.Wolf, K.H.). Elsevicr V. Amsterdam. 14:223-310.

Prcinfalk, C; Lugli, S.; Morteani, G. 1993. The magnesite in Ihe Upper Triasic Burano Evaporitic Formation of central Italy: a contribution to the controversy on sparry magnesite genesis. Terra Abstracts. EUG VII Strasbourg, France, p. 345-346

Qiushong, Z. 1988. Early Proterozoic tectonic styles and associated mineral deposits ofthe north China Platform. Precambrian Research, 39:1-29.

Quemeneur, J.M. 1974. Les gisements de magnesite du Pays Basque : cadre géologique et sédimentologique; genèse de Ia magnésite en milieu sédimentaire. Thèse de doctorat présentéc à l'Université de Paris VI. 265p (Inédit).

Rosenbcrg, P.E \& Mills, J.W. - 1966 - A mechanism for the emplacement of magnesite in dolomite. Economic Geology, 61:582-586.

Sá, J.M. 1991. Evolution gcodynamique de Ia ceinture protérozoique d'Orós, Nord-Est du Brèsil. Thèse de doctorat de 1'Univcrsité de Nancy I, 117p

Schulz, O. \& Vavtar, F. 1989. Genetic fabric interprctation of the magnésite deposit of WeiBcnstein (Hochfilzcn, Tyrol). Monograph Series Mineral Deposits. 28:115-134.

Serdyuchenko, D.P. 1975. Some Precambrian scapolite-bcaring rocks evolved from cvaporites. Lithos; $S: \mid-l$

Shaw, D.M. - 1960- The gcochcmistry of scapolile. Parts 1 et 2. Journal Petrology, 1:218 -285.

Siegl.W. 1984. Rcflexions on the Origin of Sparry Magnesite Deposits. In Syngenesis and Epigenesis in the Formation of Mineral Deposits (eds. A. Wauschkuhn; C.Kluth; R.A Zimmermann.). Springer-Verlag Berlin Heidelberg. 177-182.

Svenningscn, O. M. 1994. Tectonic Significance ofthe metaevaporitic magnesite and scapolite deposils in the Sevc Nappes, Sarek Mts., Swcdish Caledonides. Tectonophysics, 231:33-44.

Tufar, W.; Gieb, J.; Schmidt, R.S.; Möller, P.; Pohl, W.; Hiedler, H.; Olsacher, A. 1989. Formation of magnesite in the Radenthein (Carinthia/Auslria) type locality. Monograph Series Mineral Deposits. 28:135-171.

Valdiya, K.S. 1968. Origin of the magnesite deposits of Southern Pithoragarh, Kumaun Himalaya, índia. Economic Geology. 63:924-934.

Vanko, D.A \& Bischop, F.C. 1982. Occurence and origin of marialitic scapolite in the Humboldt lopolilh, N.W. Nevada. Contrib. Mineralogy. Petrology; 81: 277-289.

Van Schmus, W.R.; Brilo Neves, B. B.; Hacksapacher, P.; Babinski, M. 1995. U/Pb and Sm/Nd geochronologic siudies of the easlern Borborema Province, Norlheaslern Brazil: inilial conclusions. J. South American Earth Sciences, 8, N 3/4, pp. 267-288.

Velasco, F.; Pcsquera, A.; Olmedo, F. 1987. A contribution lo the ore genesis of lhe magnesite deposil of Eugui, Navarra (Spain). Mineralium Deposita, 22:33-41.

Veizer, J.; Clayion, R.N.; Hinlon, R.W.; Brunn, V.V.; Mason, T.R.; Buck, S.G.; Hoefs, J. 1990 Geochemistry of Precambrian carbonates: 3-shelf seas and non-marine environments of the Archcan. Geochim. Cosmochim. Acta. 54;2717-2729.

Veizer, J.; Clayion, R.N.; Hinlon, R.W. 1992. Geochemistry of Precambrian carbonates: IV. Early Paleoprolerozoic ( $2.25 \pm 0,25 \mathrm{Ga}$ ) seawalcr. Geochim. Cosmochim. Acta. 56: 875-885.

Von der Borg, C.G. 1965. The dislribulion and preliminary geochemistry of modern carbonate sediments ofthe Coorong Área, south Austrália. Geoch. Cosmoch. Acta, 29:781-799.

Von der Borg, C.G. 1976. Stratigraphy and formation of Holocene dolomitic carbonate deposit of the Coorong Area, south Australia. Journ. Sedimentary Petrology, 46(4):956-966.

Manuscrito A-968

Recebido em 24 de março de 1998 